\title{
Design and Synthesis of Novel Arylketo-containing P1-P3 Linked Macro- cyclic BACE-1 Inhibitors
}

\author{
Veronica Sandgren ${ }^{1}$, Oscar Belda ${ }^{2}$, Ingemar Kvarnström ${ }^{1}$, Jimmy Lindberg ${ }^{2}$, Bertil Samuelsson ${ }^{2}$ \\ and Anders Dahlgren,"* \\ ${ }^{I}$ Department of Chemistry, Linköping University, S-581 83 Linköping, Sweden; ${ }^{2}$ Medivir AB, Lunastigen 7, S-141 44 \\ Huddinge, Sweden
}

\begin{abstract}
A series of arylketo-containing P1-P3 linked macrocyclic BACE-1 inhibitors were designed, synthesized, and compared with compounds with a previously known and extensively studied corresponding P2 isophthalamide moiety with the aim to improve on permeability whilst retaining the enzyme- and cell-based activities. Several inhibitors displayed substantial increases in Caco-2 cell-based permeability compared to earlier synthesized inhibitors and notably also with retained activities, showing that this approach might yield BACE-1 inhibitors with improved properties.
\end{abstract}

Keywords: Alzheimer's disease, BACE-1 inhibition, cellular permeability, macrocycles, ring-closing metathesis, X-ray structure.

\section{INTRODUCTION}

Alzheimer's disease (AD) is a devastating neurodegenerative disorder and the most common form of dementia among the elderly. It is believed that 24 million people worldwide suffer from the disease [1], and with an aging population the number of patients with $\mathrm{AD}$ is expected to rise. To develop disease-modifying drugs is therefore of paramount importance. The pathological findings associated with $\mathrm{AD}$ are insoluble extracellular amyloid $\beta$-plaques, consisting of $A \beta$-peptides, and intracellular neurofibrillary tangles found in the brain [2]. The human aspartic protease BACE-1 ( $\beta$-secretase) initiates the cleavage of the amyloid precursor protein (APP) followed by $\gamma$-secretase which generates the A $\beta$-peptides, where BACE- 1 catalyzes the ratelimiting step in this sequence [3]. This, together with the knowledge that BACE-1 knockout mice are viable and fertile, suggests that inhibition of BACE-1 could be a promising therapeutic target for the treatment of $\mathrm{AD}[4,5]$. However, the development of potent and selective BACE-1 inhibitors able to cross the blood-brain barrier (BBB) and avoid Pglycoprotein (P-gp) efflux shuffling has proven to be challenging [6, 7]. Notably though, in December 2013, Merck announced that they plan to initiate a new phase III study for their BACE-1 inhibitor MK-8931. Also, in September 2014 AstraZeneca and Eli Lilly \& Company announced that they will develop and commercialize AZD3293. This proves that it is possible to design and synthesize potent and selective BACE-1 inhibitors [8].

Earlier studies in our laboratory [9] led to the development of a series of macrocyclic BACE-1 inhibitors, e.g. compound 1a (Fig. 1), where both promising enzymatic and cell-based activities were observed. However, as these

*Address correspondence to this author at the Department of Chemistry, Linköping University, S-581 83 Linköping, Sweden;

Tel: +46 13 281000; Fax: +46 13 281399; E-mail: andda@ifm.liu.se inhibitors suffered from low permeability, we have in this study focused on improving the cell-based permeability by replacing the terminal amide of the $\mathrm{P} 2$ isophthalamide moiety with an acetophenone-type ketone group, thus rendering the molecules less peptidic (Fig. 1). Earlier studies have shown that the amide carbonyl oxygen of the $\mathrm{P} 2$ isophthalamide moiety forms a hydrogen bond with $\mathrm{Thr} 232$ in BACE1 , whilst the amide nitrogen does not make significant interactions with the enzyme $[10,11]$. Moreover, it has been shown that the amide group of the P2 isophthalamide moiety can be replaced by a carbon chain, without significant loss in potency $[6,11]$, which renders the BACE-1 10s loop in a closed conformation with a hydrogen bond between Ser10 and Thr232, stabilizing the closed conformation. We thus hypothesized that an acetophenone-type carbonyl would provide an advantageous bioisostere to the amide group in this position, resulting in higher permeability through making less overall hydrogen bonds and provide inhibitors with retained good activity compared to their isophthalamide analogues. Also, further attempts to improve the cell-based permeability were performed by replacing the P2 sulfonamide functionality with a less polar methyl group.

We have also investigated the effect of replacing the oxygen atom in the macrocyclic ring structure, used in some of our earlier inhibitors [9], with a carbon atom and in the P2' position replacing the 3-isopropylbenzylamine moiety with 2-(5-(tert-butyl)oxazol-2-yl)propan-2-amine, aiming at improving the overall pharmacokinetic properties.

\section{RESULTS AND DISCUSSION}

\section{Chemistry}

The target compounds 28-36 were prepared according to Schemes 1-4 (see also Table 1). The synthesis of compound $\mathbf{8}$ is outlined in Scheme 1. Compound $\mathbf{2}$ was synthesized according to an already published procedure [9]. The acetal in 2 was hydrolyzed with $\mathrm{AcOH}$ (aq.) at $60{ }^{\circ} \mathrm{C}$ to give the 


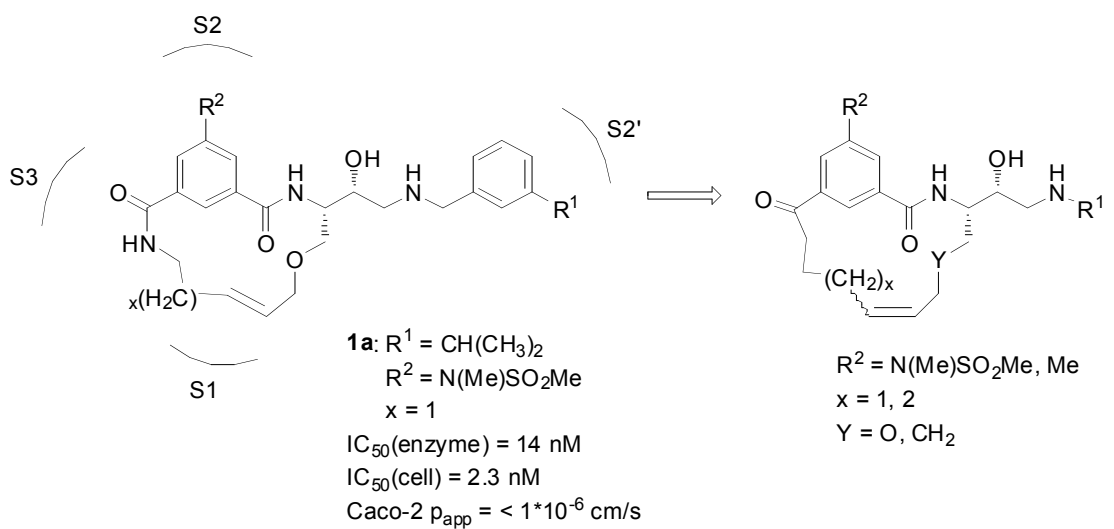

Fig. (1). Lead compound 1a together with a general structure of the target macrocycles presented in this paper.
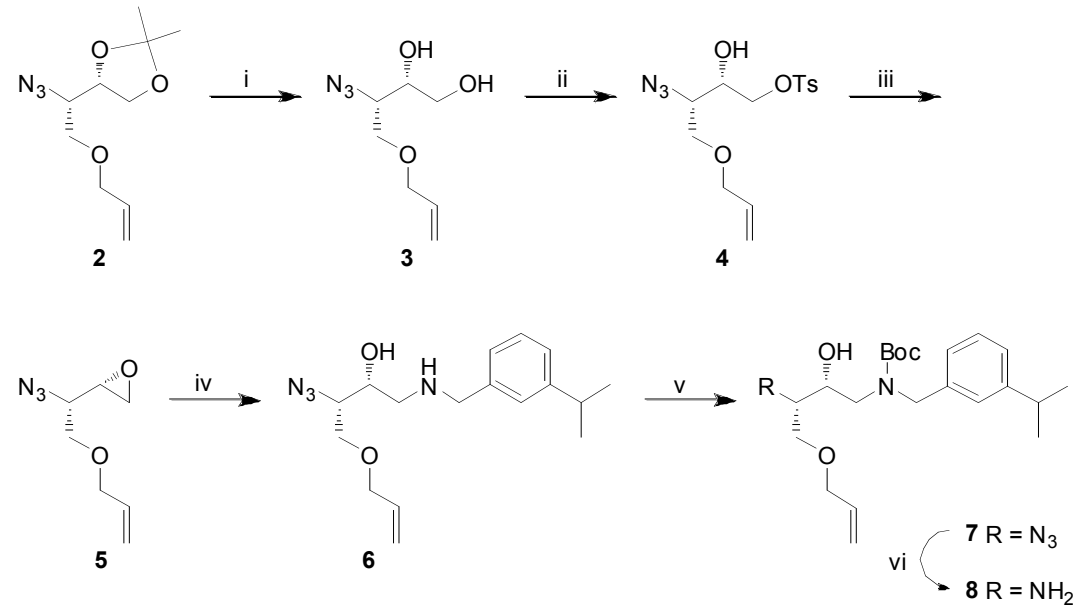

Scheme 1. Synthesis of building block 8. Reagents and conditions: (i) $\mathrm{AcOH}$ (aq.), $60{ }^{\circ} \mathrm{C}, 3 \mathrm{~h}, 78 \%$; (ii) $\mathrm{TEA}, \mathrm{Bu} \mathrm{S}_{2} \mathrm{SnO}, p$-TsCl, dry $\mathrm{DCM}$, rt, 3.5 h, 74\%; (iii) $\mathrm{K}_{2} \mathrm{CO}_{3}, \mathrm{MeOH}, 0{ }^{\circ} \mathrm{C}$ to rt, $3 \mathrm{~h}, 84 \%$; (iv) 3-isopropyl-benzylamine, TEA, $\mathrm{MeOH}, 30{ }^{\circ} \mathrm{C}, 44 \mathrm{~h}, 56 \%$; (v) $\mathrm{Boc} 2 \mathrm{O}, \mathrm{TEA}, \mathrm{MeOH}$, rt, 1 h, 81\%; (vi) 1,3-propanedithiol, TEA, Aliquat 336, MeOH, rt, 6 days, 76\%.

diol $\mathbf{3}$ in $78 \%$ yield. The primary hydroxyl group in $\mathbf{3}$ was selectively tosylated using $p$ - $\mathrm{TsCl}, \mathrm{Bu}_{2} \mathrm{SnO}$, and TEA in dry DCM [12] to generate compound 4 (74\%). The tosylated compound was then converted into the corresponding epoxide 5 in $84 \%$ yield, using $\mathrm{K}_{2} \mathrm{CO}_{3}$ in $\mathrm{MeOH}$. The epoxide was thereafter opened with 3-isopropylbenzylamine furnishing compound 6 in $56 \%$ yield. For purification reasons, the prepared amine was protected using $\mathrm{Boc}_{2} \mathrm{O}$ and TEA in $\mathrm{MeOH}$ to give compound $7(81 \%)$. Finally, the azide 7 was reduced using 1,3-propanedithiol, TEA, and Aliquat 336 in $\mathrm{MeOH}$ to afford the amine 8 in $76 \%$ yield.

The synthesis of compounds $\mathbf{1 8 a}, \mathbf{1 8 b}$, and $\mathbf{1 9}$ is depicted in Scheme 2. 2,3-O-Isopropylidene-D-glyceraldehyde was synthesized according to a literature procedure [13] and the addition of a freshly prepared Grignard reagent, pent-4enylmagnesium bromide or hex-5-enylmagnesium bromide, produced the two compounds $9 \mathbf{a}$ and $\mathbf{9 b}$ in diastereomeric mixtures which were subsequently separated. In the case of 9b we had enough material of the correct diastereomer after the chromatography separation to proceed directly to $\mathbf{1 2 b}$. (The various stereoisomers were identified by NMR analyses). The hydroxyl group in $(S, R)-9$ a was reacted with $\mathrm{PPh}_{3}$, DIAD, and $p$-nitrobenzoic acid in THF, furnishing compound 10a in $91 \%$ yield. The benzoate ester was cleaved using $\mathrm{NaOMe}$ in $\mathrm{MeOH}$ to give the inverted alcohol 11a in
$68 \%$ yield. Mitsunobu conditions, utilizing DPPA [14], generated the azide 12a with inversion of configuration in $98 \%$ yield. The acetal in $\mathbf{1 2 a}$ was hydrolyzed in $\mathrm{AcOH}$ (aq.) at $60{ }^{\circ} \mathrm{C}(74 \%)$ and the primary alcohol in the formed diol 13a was selectively tosylated, using TEA, $\mathrm{Bu}_{2} \mathrm{SnO}$, and $p$ - $\mathrm{TsCl}$ in DCM and DMF, to give compound 14a in $84 \%$ yield. The epoxide 15a was prepared in $90 \%$ yield using $\mathrm{Na}_{2} \mathrm{CO}_{3}$ in $\mathrm{MeOH}$, and was then opened with 3-isopropylbenzylamine and TEA in $\mathrm{MeOH}$ at $30{ }^{\circ} \mathrm{C}$ to give compound 16a $(61 \%)$. Compound 16b was synthesized, with comparable yields, in the same manner from $\mathbf{1 2 b}$. Finally, reduction of the azide group in compounds $\mathbf{1 6 a}, \mathbf{1 6 b}$, and 17 was achieved using 1,3-propanedithiol, TEA, and Aliquat 336 in $\mathrm{MeOH}$, providing the amines $\mathbf{1 8 a}$ and $\mathbf{1 8 b}$ in $83 \%$ and $81 \%$ yield, respectively. As an alternative synthetic route, for purification reasons, compound 16a was treated with $\mathrm{Boc}_{2} \mathrm{O}$ and TEA in $\mathrm{MeOH}$ to afford the Boc-protected compound 17 in $97 \%$ yield. 17 was then reduced as above, yielding 19 (88\%).

The synthesis of target compounds $\mathbf{2 8 a}$ and $\mathbf{2 8 b}$ is outlined in Scheme 3. The compounds were synthesized using two slightly different routes, depending on if the amine (see Scheme 2) was Boc-protected before the peptide coupling step or after. Compound 20a was synthesized according to a reported procedure [15] and the carboxylic acid was selectively reduced with $\mathrm{BH}_{3} \cdot \mathrm{SMe}_{2}$ in dry THF to give the alcohol 


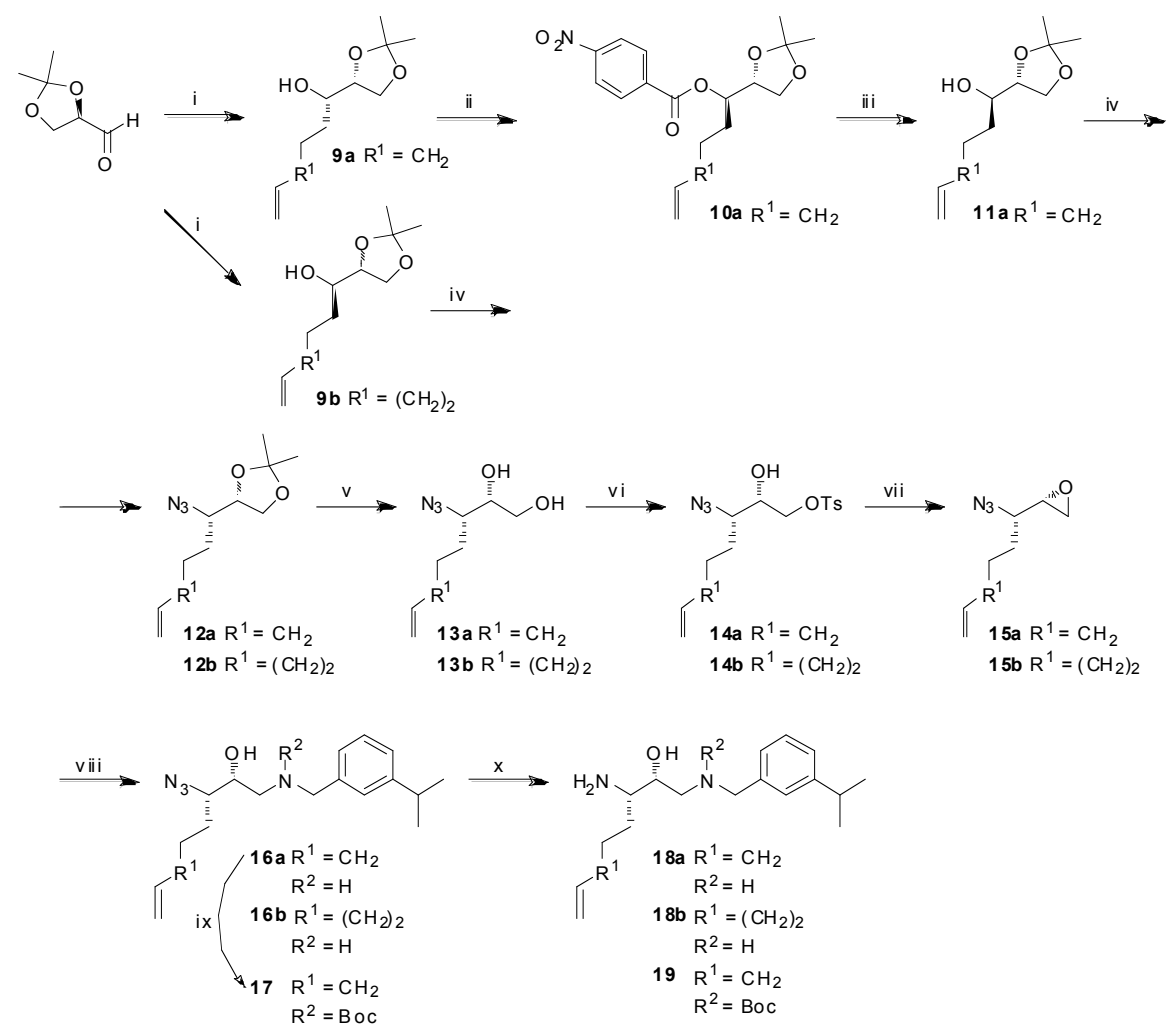

Scheme 2. Synthesis of building blocks 18a-b and 19. Reagents and conditions: (i) pent-4-enylmagnesium bromide or hex-5-enylmagnesium bromide in $\mathrm{THF}, \mathrm{Et}_{2} \mathrm{O}$ (dry), $-30{ }^{\circ} \mathrm{C}$ to rt, $21 \mathrm{~h}, 80 \%$ and $87 \%$, respectively; (ii) $p$-nitrobenzoic acid, $\mathrm{DIAD}_{\mathrm{PPh}}$, THF, rt, overnight, $91 \%$; (iii) $\mathrm{NaOMe}, \mathrm{MeOH}, \mathrm{rt}, 1 \mathrm{~h} 45 \mathrm{~min}, 68 \%$; (iv) DPPA, $\mathrm{PPh}_{3}$, DIAD, THF (dry), $-30{ }^{\circ} \mathrm{C}$ to rt, $24 \mathrm{~h}, 98 \%$ and $88 \%$, respectively; (v) $70 \%$ AcOH (aq.), $60{ }^{\circ} \mathrm{C}, 3 \mathrm{~h}, 74 \%$ and quant., respectively; (vi) TEA, $\mathrm{Bu}_{2} \mathrm{SnO}, p$-TsCl, DCM, DMF, rt, overnight, 84\% and 88\%, respectively; (vii) $\mathrm{Na}_{2} \mathrm{CO}_{3}, \mathrm{MeOH}, 0{ }^{\circ} \mathrm{C}$ to rt, $24 \mathrm{~h}, 100 \%$ and 97\%, respectively; (viii) 3-isopropylbenzylamine, TEA, $\mathrm{MeOH}, 30{ }^{\circ} \mathrm{C}, 24 \mathrm{~h}, 61 \%$ and $53 \%$, respectively; (ix) $\mathrm{Boc}_{2} \mathrm{O}$, TEA, MeOH, rt, 1.5 h, 97\%; (x) 1,3-dipropanedithiol, TEA, aliquat 336, MeOH, rt, 5 days, 83\%, 81\%, and 88\%, respectively.

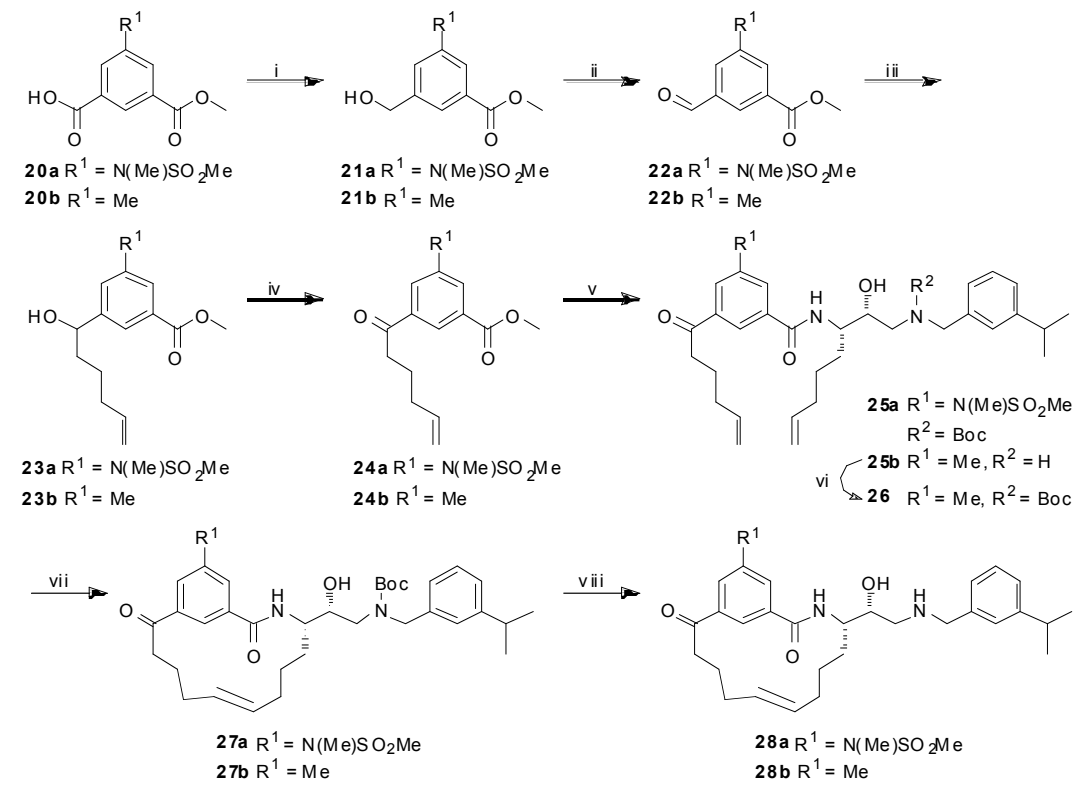

Scheme 3. Synthesis of target compounds 28a and 28b. Reagents and conditions: (i) $\mathrm{BH}_{3} \mathrm{SMe}_{2}, \mathrm{THF}$ (dry), Ar, $0{ }^{\circ} \mathrm{C}$ to rt, $24 \mathrm{~h}, 95 \%$ and $69 \%$, respectively; (ii) $\mathrm{SO}_{3}$-pyridine, TEA, DMSO (dry), rt, $1.5 \mathrm{~h}, 84 \%$ and 73\%, respectively; (iii) pent-4-enylmagnesium bromide in THF, $\mathrm{Et}_{2} \mathrm{O}$ (dry), $0{ }^{\circ} \mathrm{C}, 3 \mathrm{~h}, 65 \%$ and $79 \%$, respectively; (iv) Dess-Martin periodinane, DCM, rt, $24 \mathrm{~h}, 76 \%$ and $89 \%$, respectively; (v) (a) LiOH (aq.), dioxane, rt, $3 \mathrm{~h}$; (b) compound 19 or 18a, HATU, DIPEA, DMF, $0{ }^{\circ} \mathrm{C}$ to rt, $24 \mathrm{~h}, 89 \%$ and $85 \%$ over two steps, respectively; (vi) $\mathrm{Boc}_{2} \mathrm{O}, \mathrm{TEA}, \mathrm{MeOH}, \mathrm{rt}, 3 \mathrm{~h}, 65 \%$; (vii) Hoveyda-Grubbs $2^{\text {nd }}$ generation, DCM (dry), reflux, $24 \mathrm{~h}, 21 \%$ and $47 \%$, respectively; (viii) Et $\mathrm{SiH}$, TFA, DCM, rt, $1 \mathrm{~h}, 91 \%$ and $91 \%$, respectively. 

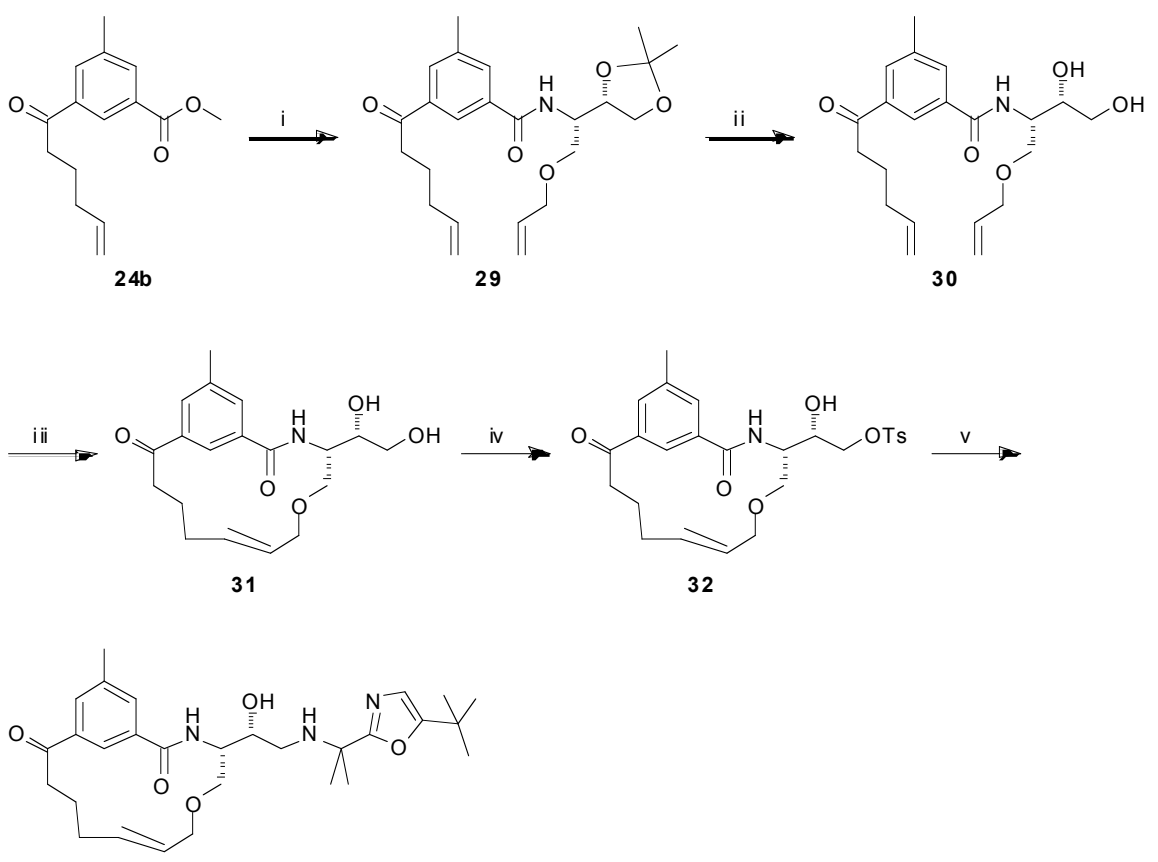

33

Scheme 4. Synthesis of target compound 33. Reagents and conditions: (i) (a) LiOH (aq.), dioxane/ $\mathrm{H}_{2} \mathrm{O}, 6$ h; (b) $(S)-2-($ allyloxy)-1-((S)-2,2dimethyl-1,3-dioxolan-4-yl)ethanamine, HATU, DIPEA, DMF, 4 h, 57\% over two steps; (ii) 80\% AcOH, $60{ }^{\circ} \mathrm{C}, 1$ h, 95\%; (iii) HoveydaGrubbs 2nd generation, DCM (dry), reflux, 16 h, 88\%; (iv) TEA, $\mathrm{Bu}_{2} \mathrm{SnO}, p$-TsCl, DCM, DMF, rt, overnight, 57\%; (v) 2-(5-(tertbutyl)oxazol-2-yl)propan-2-amine, DIPEA, EtOH, reflux, 4 days, $5 \%$.

21a in 95\% yield. A Parikh-Doering oxidation [16] generated the aldehyde 22a (95\%) and the subsequent addition of the Grignard reagent pent-4-enylmagnesium bromide furnished the alcohol 23a in $65 \%$ yield. This compound was oxidized to the corresponding ketone $24 \mathbf{a}$ in $76 \%$ yield using Dess-Martin periodinane in DCM [17]. The ester functionality in $\mathbf{2 4 a}$ was hydrolyzed using aqueous $\mathrm{LiOH}$ in dioxane and the resulting carboxylic acid was coupled with compound 19 using HATU and DIPEA in DMF to afford compound 25a in $89 \%$ yield over two steps. Compound $\mathbf{2 5 b}$ was synthesized in the same manner as $\mathbf{2 5} \mathbf{a}$ using commercially available 20b instead of 20a, and amine 18a instead of 19 in the coupling reaction. For purification reasons, the amino group in compound 25b was protected using $\mathrm{Boc}_{2} \mathrm{O}$ and TEA in $\mathrm{MeOH}$ to give compound 26 in 69\% yield. A ringclosing metathesis protocol was performed on compound 25a and 26 using Hoveyda-Grubbs $2^{\text {nd }}$ generation catalyst in refluxing DCM to furnish the macrocyclic compounds 27a and $27 \mathbf{b}$ in $21 \%$ and $47 \%$ yield, respectively. The cyclization resulted in exclusive formation of the trans isomers, as confirmed by ${ }^{1} \mathrm{H}-\mathrm{NMR}$ analyses. Finally, deprotection of the Boc group was achieved with $\mathrm{Et}_{3} \mathrm{SiH}$ and TFA in DCM to give the two target compounds 28a and 28b in 91\% yield in both cases. Targets 34 and 35 (see Table 1) were synthesized according to the same synthetic route as $\mathbf{2 8 a}$, using amine $\mathbf{8}$ instead of 19 and the methyl ester 24b instead of 24a for compound 35. Target 36 (see Table 1) was synthesized in the same manner as $\mathbf{2 8 b}$ using amine $\mathbf{1 8 b}$ instead of $\mathbf{1 8 a}$.

When using the route described in Scheme 3, the ringclosing metathesis step was unsuccessful when trying to synthesize target $\mathbf{3 3}$ (see Table 1). The reason for this is at this stage unknown. Therefore, a different synthetic route was outlined for 33, as shown in Scheme 4. The methyl ester functionality in compound $\mathbf{2 4 b}$ was hydrolyzed using $\mathrm{LiOH}$ (aq.) in dioxane $/ \mathrm{H}_{2} \mathrm{O}$ to furnish the corresponding carboxylic acid, which was subsequently used in a peptide coupling step with the amine (S)-2-(allyloxy)-1-((S)-2,2-dimethyl-1,3dioxolan-4-yl)ethanamine [9] using HATU and DIPEA in DMF to give compound $\mathbf{2 9}$ in $57 \%$ yield. The acetal was hydrolyzed with $80 \% \mathrm{AcOH}$ to generate the diol 30 in $95 \%$ yield. The ring-closing metathesis protocol, using HoveydaGrubbs $2^{\text {nd }}$ generation catalyst in refluxing DCM, was now successful and rendered the macrocycle 31 in $88 \%$ yield. The primary hydroxyl group in $\mathbf{3 1}$ was tosylated by the use of TEA, $\mathrm{Bu}_{2} \mathrm{SnO}$, and $p$-TsCl in DCM and DMF, which furnished compound 32 (57\%). Finally, the tosylated compound was reacted with the amine 2-(5-(tert-butyl)oxazol-2yl)propan-2-amine (see supp. info.) and DIPEA in refluxing EtOH to give the target compound $\mathbf{3 3}$ in 5\% yield.

\section{Structure Activity Relationships}

All target compounds were screened against BACE-1, both in enzyme- and cell-based assays, and the $\mathrm{IC}_{50}$ values are shown in Table 1, along with Caco- $2 p_{\text {app }}$ values for selected compounds. The macrocycles were all 15-membered, except for compound $\mathbf{3 6}$ which was 16-membered.

Replacement of the terminal P2 amide functionality in the lead compound 1a [9] with a keto group resulted in target product 34 which showed retained potencies against BACE1 although without displaying improved permeability. It has earlier been found that BACE-1 inhibitors with a sulfonamide substituted isophthalamide in the P2 position are substrates for P-gp efflux [18], which could explain the low permeability of compound 34. Replacement of the P2 sulfonamide functionality with a less polar methyl group 
Design and Synthesis of Novel Arylketo-containing P1-P3

The Open Medicinal Chemistry Journal, 2015, Volume 9

17

Table 1. BACE-1 inhibition data and cell permeability values.

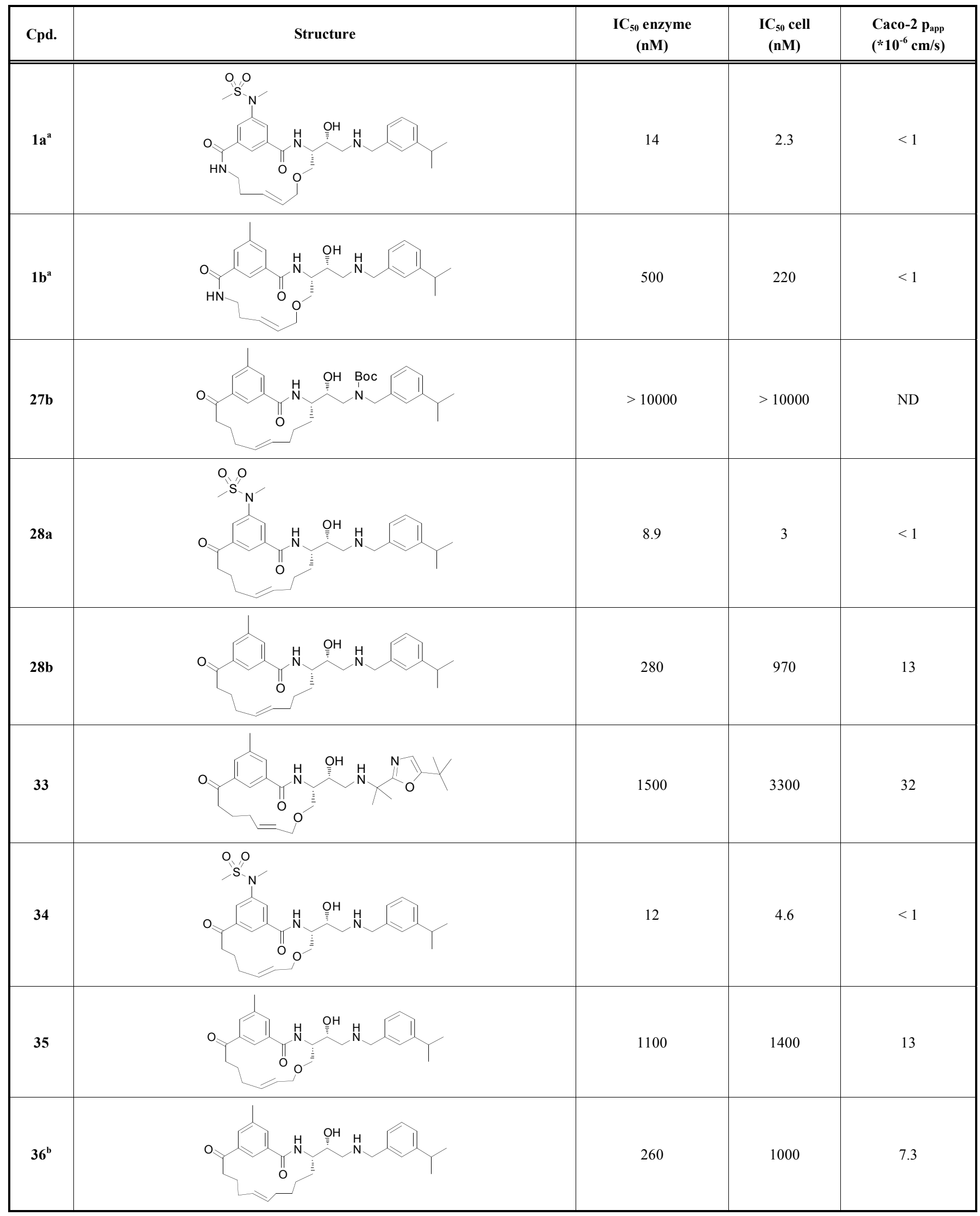

a Previously reported by our laboratory

${ }^{\mathrm{b}} 16$-membered macrocycle 


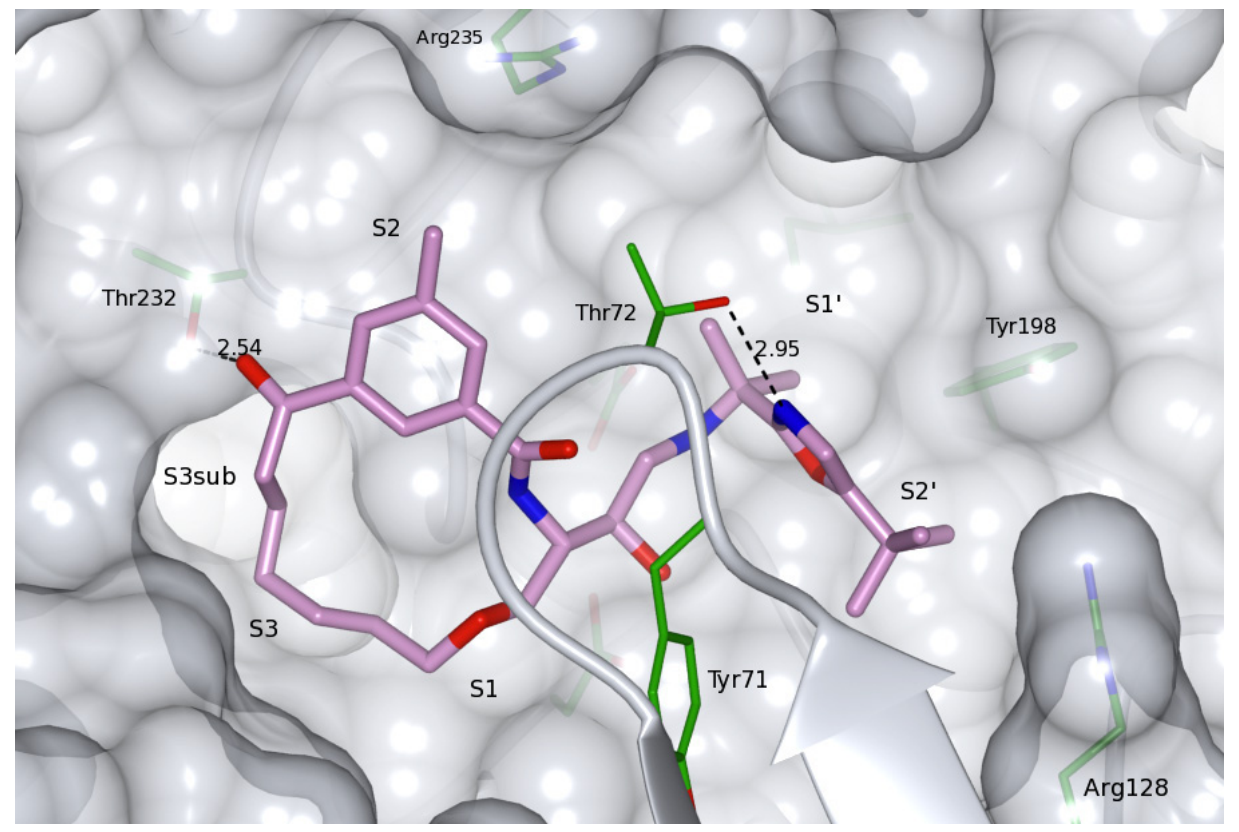

Fig. (2). Compound 33 bound to the active site of BACE-1 (PDB id: 4GMI).

furnished compound $\mathbf{3 5}$, resulting in a significantly improved $\left(\mathrm{p}_{\mathrm{app}}=13 \times 10^{-6} \mathrm{~cm} / \mathrm{s}\right)$ permeability. However, with the P2 sulfonamide replaced with a methyl group the BACE-1 activity was substantially reduced, but this compound exhibited comparable BACE-1 activities as the amide analogue $\mathbf{1 b}$ [9] (Table 1) published earlier (a BACE-1 $\mathrm{IC}_{50}$ value of 1100 vs. $500 \mathrm{nM}$ and a cell-based $\mathrm{IC}_{50}$ value of 1400 vs. $220 \mathrm{nM}$, respectively), but with significantly better permeability (a Caco- 2 value of $13 \times 10^{-6} \mathrm{~cm} / \mathrm{s}$, as mentioned above, vs. $<1$ $\times 10^{-6} \mathrm{~cm} / \mathrm{s}$, respectively). In-house studies have shown that the introduction of a oxazole group (see supplementary material) in the $\mathrm{P} 2^{\prime}$ position can give rise to highly active compounds and with improved permeability. Introduction of this oxazole group provided compound $\mathbf{3 3}$ which exhibited additional improvement in permeability compared with inhibitor 35 whilst retaining enzyme- and cell-based activity compared with compound 35. The X-ray structure of $\mathbf{3 3}$ (PDB id: 4GMI) in complex with BACE-1 shows that the gem-methyl groups shielding the secondary nitrogen atom are well accommodated for and, as such, are not exerting any steric impediment on compound binding (Fig. 2). Moreover, the P2' tert-butyl substituted oxazole has a good fit to the S2' subsite, including a hydrogen bond to Thr72 of the flap.

Generally, we have noted that replacing the macrocyclic ether oxygen with a carbon in these inhibitors often results in increased potency [19]. However, the carbon analogue to compound 34, inhibitor 28a, showed similar potent activities (a BACE-1 IC $_{50}$ value of 8.9 vs. $12 \mathrm{nM}$ and a cell-based $\mathrm{IC}_{50}$ value of $3.0 \mathrm{vs} .4 .6 \mathrm{nM}$, respectively). As expected, with a P2 sulfonamide moiety, compound 28a also displayed a similar low Caco-2 permeability value $\left(<1 \times 10^{-6} \mathrm{~cm} / \mathrm{s}\right)$. As foreseen, the Boc-protected compound $\mathbf{2 7 b}$ was inactive. (It is well established that hydroxyethylamine-based BACE-1 inhibitors bind to the catalytic aspartates Asp32 and Asp228 via the protonated amino and hydroxy groups [9, 20, 21]). Compound $\mathbf{2 8 b}$, incorporating a toluene core in the P2 position, displayed an improved potency compared to its analogue 35 ( $\mathrm{IC}_{50} 280$ vs. $1100 \mathrm{nM}$, respectively) and equal permeability $\left(\mathrm{p}_{\mathrm{app}}=13 \times 10^{-6} \mathrm{~cm} / \mathrm{s}\right)$. The 16 -membered macrocycle 36 showed similar activity and permeability as its corresponding 15-membered macrocycle $\mathbf{2 8 b}$. Attempts to synthesize the corresponding 14-membered macrocycle were unsuccessful, likely due to a high ring strain of the target product.

\section{CONCLUSION}

A novel series of macrocyclic BACE-1 inhibitors incorporating a P2/P3 keto functionality was investigated, with some inhibitors showing highly promising low nanomolar activities against the BACE-1 enzyme and in the cell-based assay. Moreover, several inhibitors exhibited improved cellbased permeability compared to inhibitors previously synthesized, but, not unexpectedly, these target compounds displayed decreased potency due to replacement of the sulfonamide functionality in the $\mathrm{P} 2$ position with a methyl group, where the sulfonamide moiety has been shown to be important for the activity in this type of inhibitor compounds. In summary, improved permeability could be achieved compared to earlier published inhibitors from our group whilst retaining the overall BACE-1 inhibitory activities.

Further work on this series is highly warranted exploring sulfonamide replacements in the P2-position, e.g. by use of small lipophilic groups and by introducing potencyenhancing lipophilic substituents protruding into the S3 sub pocket.

\section{EXPERIMENTAL SECTION}

\section{General}

NMR-spectra were recorded on a Varian $300 \mathrm{MHz}$ instrument using $\mathrm{CDCl}_{3}, \mathrm{CD}_{3} \mathrm{OD}$ or DMSO- $d_{6}$ as solvents. Thin layer chromatography (TLC) was carried out on Merck precoated $60 \mathrm{~F}_{254}$ plates using UV-light and charring with ethanol/sulfuric acid/ $p$-anisaldehyde/acetic acid $90: 3: 2: 1$, or 
a solution of $0.5 \%$ ninhydrin in ethanol, for visualization. Flash column chromatography was performed using silica gel 60 (0.040-0.063 mm, Merck). Organic phases were dried over anhydrous magnesium sulfate. Optical rotations were measured using a Perkin-Elmer 141 polarimeter at $22{ }^{\circ} \mathrm{C}$. Gradient LC-MS was performed on a Gilson system (column: Phenomenex C18, $100 \times 21 \mathrm{~mm}, 5 \mu \mathrm{m}$ for preparative runs and $x B$ ridge ${ }^{\mathrm{TM}} \mathrm{C} 18,50 \times 4.6 \mathrm{~mm}, 2.5 \mu \mathrm{m}$ for analytical runs; pump: Gilson gradient pump 322; UV/VIS-detector: Gilson 152; MS detector: Thermo Finnigan Surveyor MSQ; Gilson Fraction Collector FC204) using acetonitrile with $0.05 \%$ formic acid and deionized water with $0.05 \%$ formic acid as mobile phases. High resolution mass spectra (HRMS) were recorded on a Waters Synapt HDMS instrument equipped with an electrospray interface.

\section{BACE-1 Enzyme Assay}

The BACE-1 assay was performed as previously described [22].

\section{BACE-1 Cell Assay}

The cell-based assay was performed as previously described [23].

\section{Caco-2 Assay}

The permeability coefficients $\left(\mathrm{p}_{\mathrm{app}}\right)$ were performed as previously described [24].

\section{LC-MS Purity Measurements}

Chromatography system A. Column: Phenomenex C18, 50 x $4.6 \mathrm{~mm}, 3 \mu \mathrm{m}$; pump: Gilson gradient pump 322; UV/VIS-detector: Gilson 152; MS detector: Thermo Finnigan Surveyor MSQ; Software: Gilson Unipoint 4.0 and Xcalibur 1.3. Mobile phase A: $10 \mathrm{mM} \mathrm{NH}_{4} \mathrm{OAc}$ in water; mobile phase B: $10 \mathrm{mM} \mathrm{NH}_{4} \mathrm{OAc}$ in $90 \%$ acetonitrile; gradient: $20-100 \%$ B over $6 \mathrm{~min}$ at $1 \mathrm{~mL} / \mathrm{min}$ followed by $100 \%$ of $B$ for $4 \mathrm{~min}$ at $1 \mathrm{~mL} / \mathrm{min}$. Peaks were detected at $254 \mathrm{~nm}$.

Chromatography system B. Column: XBridge C8, $50 \mathrm{x}$ $4.6 \mathrm{~mm}, 2.5 \mu \mathrm{m}$; pump: Gilson gradient pump 322; UV/VISdetector: Gilson 152; MS detector: Thermo Finnigan Surveyor MSQ; Software: Gilson Unipoint 4.0 and Xcalibur 1.3. Mobile phase A: $10 \mathrm{mM} \mathrm{NH}_{4} \mathrm{OAc}$ in water; mobile phase B: $10 \mathrm{mM} \mathrm{NH} \mathrm{m}_{4} \mathrm{OAc}$ in $90 \%$ acetonitrile; gradient: $40-100 \% \mathrm{~B}$ over $7 \mathrm{~min}$ at $1 \mathrm{~mL} / \mathrm{min}$ followed by $100 \%$ of B for $3 \mathrm{~min}$ at $1 \mathrm{~mL} / \mathrm{min}$. Peaks were detected at $254 \mathrm{~nm}$.

\section{SYNTHETIC PROCEDURES}

(2S,3S)-4-(Allyloxy)-3-azidobutane-1,2-diol (3). Compound 2 (1.82 g, $8.0 \mathrm{mmol})$ was dissolved in $\mathrm{AcOH} / \mathrm{H}_{2} \mathrm{O}$ $(40: 15 \mathrm{~mL})$ and the solution was stirred for 3 hours at $60{ }^{\circ} \mathrm{C}$. The mixture was concentrated, co-evaporated with toluene and purified using flash column chromatography (toluene/EtOAc $1: 1)$ to give compound 3 (1.17 g, 78\%) as a colorless oil. ${ }^{1} \mathrm{H}-\mathrm{NMR}\left(\mathrm{CDCl}_{3}, 300 \mathrm{MHz}\right): \delta 2.73$ (bs, $\left.2 \mathrm{H}\right)$, 3.58-3.66 (m, 2H), 3.67-3.77 (m, 4H), $4.03(\mathrm{~d}, J=5.7 \mathrm{~Hz}$, 2H), 5.19-5.32 (m, 2H), 5.82-5.95 (m, 1H); ${ }^{13} \mathrm{C}-\mathrm{NMR}$ $\left(\mathrm{CDCl}_{3}, 75.5 \mathrm{MHz}\right): \delta 62.1,63.6,70.0,71.9,72.6,117.9$, 134.0. MS-analysis resulted in decomposition. No mass peak could be detected.
(2S,3S)-4-(Allyloxy)-3-azido-2-hydroxybutyl 4-methyl benzenesulfonate (4). TEA $(830 \mu \mathrm{L}, 6.0 \mathrm{mmol}), \mathrm{Bu}_{2} \mathrm{SnO}$ (124 mg, $0.5 \mathrm{mmol})$ and $p$-TsCl (1.13 g, $5.9 \mathrm{mmol})$ were added to a solution of compound $3(930 \mathrm{mg}, 4.9 \mathrm{mmol})$ in dry DCM $(30 \mathrm{~mL})$. The mixture was stirred for 3.5 hours at room temperature. The solution was thereafter diluted with DCM, washed two times with brine and the organic phase was dried, filtered and concentrated. Purification using flash column chromatography (toluene/EtOAc 19:1) gave compound $4(1.25 \mathrm{~g}, 74 \%)$ as a colorless oil. ${ }^{1} \mathrm{H}-\mathrm{NMR}\left(\mathrm{CDCl}_{3}\right.$, $300 \mathrm{MHz}): \delta 2.45(\mathrm{~s}, 3 \mathrm{H}), 2.87(\mathrm{bs}, 1 \mathrm{H}), 3.55-3.61(\mathrm{~m}, 1 \mathrm{H})$, $3.66(\mathrm{dd}, J=6.0,10.2 \mathrm{~Hz}, 1 \mathrm{H}), 3.75(\mathrm{dd}, J=3.6,10.2 \mathrm{~Hz}$, $1 \mathrm{H}), 3.83-3.90(\mathrm{~m}, 1 \mathrm{H}), 4.01(\mathrm{dt}, J=1.5,5.7 \mathrm{~Hz}, 2 \mathrm{H}), 4.10$ $(\mathrm{dd}, J=5.7,10.5 \mathrm{~Hz}, 1 \mathrm{H}), 4.20(\mathrm{dd}, J=3.3,10.5 \mathrm{~Hz}, 1 \mathrm{H})$, 5.18-5.31 (m, 2H), 5.80-5.93 (m, 1H), $7.36(\mathrm{~d}, J=8.1 \mathrm{~Hz}$, $2 \mathrm{H}), 7.81(\mathrm{~d}, J=8.1 \mathrm{~Hz}, 2 \mathrm{H}) ;{ }^{13} \mathrm{C}-\mathrm{NMR}\left(\mathrm{CDCl}_{3}, 75.5 \mathrm{MHz}\right)$ : $\delta$ 21.7, 61.4, 69.5, 69.6, 71.1, 72.5, 117.7, 128.1, 130.1, $132.5,134.0,145.4$. MS-analysis resulted in decomposition. No mass peak could be detected.

(S)-2-((S)-2-(Allyloxy)-1-azidoethyl)oxirane (5). Compound 4 (1.25 g, $3.7 \mathrm{mmol})$ was dissolved in $\mathrm{MeOH}(28$ $\mathrm{mL}) . \mathrm{K}_{2} \mathrm{CO}_{3}(830 \mathrm{mg}, 6.0 \mathrm{mmol})$ was added at $0{ }^{\circ} \mathrm{C}$ and the solution was left to reach room temperature and stirred for 3 hours. $\mathrm{H}_{2} \mathrm{O}$ and DCM were added and the organic phase was dried, filtered and concentrated. The crude material was purified using flash column chromatography (toluene/EtOAc 19:1) and compound 5 (521 mg, 84\%) was collected as a colorless oil. ${ }^{1} \mathrm{H}-\mathrm{NMR}\left(\mathrm{CDCl}_{3}, 300 \mathrm{MHz}\right): \delta 2.75-2.77(\mathrm{~m}$, $1 \mathrm{H}), 2.79-2.83(\mathrm{~m}, 1 \mathrm{H}), 3.06-3.10(\mathrm{~m}, 1 \mathrm{H}), 3.46-3.51(\mathrm{~m}$, $1 \mathrm{H}), 3.58(\mathrm{dd}, J=6.3,9.9 \mathrm{~Hz}, 1 \mathrm{H}), 3.66(\mathrm{dd}, J=3.9,9.9 \mathrm{~Hz}$, $1 \mathrm{H}), 4.03$ (dt, $J=1.5,5.7 \mathrm{~Hz}, 2 \mathrm{H}), 5.18-5.21(\mathrm{~m}, 1 \mathrm{H}), 5.24-$ $5.31(\mathrm{~m}, 1 \mathrm{H}), 5.83-5.96(\mathrm{~m}, 1 \mathrm{H}) ;{ }^{13} \mathrm{C}-\mathrm{NMR}\left(\mathrm{CDCl}_{3}, 75.5\right.$ $\mathrm{MHz}): \delta$ 45.2, 50.8, 61.8, 70.0, 72.5, 117.6, 134.1. MS $(2 \mathrm{M}+\mathrm{Na})^{+}$calcd: 361.2 ; found: 360.7 .

(2R,3S)-4-(Allyloxy)-3-azido-1-((3-isopropylbenzyl) amino)butan-2-ol (6). Compound 5 (385 mg, $2.3 \mathrm{mmol}$ ) and 3-isopropylbenzylamine (510 mg, $3.4 \mathrm{mmol})$ were dissolved in $\mathrm{MeOH}(2.5 \mathrm{~mL})$. TEA (640 mL, $4.6 \mathrm{mmol})$ was added and the solution was stirred for 44 hours at $30{ }^{\circ} \mathrm{C}$. The mixture was concentrated and purified using flash column chromatography (toluene/EtOAc 3:1 + 1\% TEA) to give compound $6(405 \mathrm{mg}, 56 \%)$ as a slightly yellow oil. ${ }^{1} \mathrm{H}-\mathrm{NMR}$ $\left(\mathrm{CDCl}_{3}, 300 \mathrm{MHz}\right): \delta 1.25(\mathrm{~d}, J=6.9 \mathrm{~Hz}, 6 \mathrm{H}), 2.70(\mathrm{dd}, J=$ 8.1, $12.3 \mathrm{~Hz}, 1 \mathrm{H}), 2.83-2.94(\mathrm{~m}, 2 \mathrm{H}), 3.52-3.57(\mathrm{~m}, 1 \mathrm{H})$, $3.58-3.64(\mathrm{~m}, 1 \mathrm{H}), 3.65-3.71(\mathrm{~m}, 1 \mathrm{H}), 3.74(\mathrm{dd}, J=3.6,9.9$ $\mathrm{Hz}, 1 \mathrm{H}), 3.77(\mathrm{~d}, J=3.6 \mathrm{~Hz}, 2 \mathrm{H}), 4.02(\mathrm{dt}, J=1.5,5.7 \mathrm{~Hz}$, $2 \mathrm{H}), 5.17-5.32(\mathrm{~m}, 2 \mathrm{H}), 5.83-5.96(\mathrm{~m}, 1 \mathrm{H}), 7.09-7.18(\mathrm{~m}$, $3 \mathrm{H}), 7.22-7.28(\mathrm{~m}, 1 \mathrm{H}) ;{ }^{13} \mathrm{C}-\mathrm{NMR}\left(\mathrm{CDCl}_{3}, 75.5 \mathrm{MHz}\right): \delta$ 24.0, 34.1, 50.9, 53.8, 63.9, 68.9, 70.1, 72.3, 117.3, 125.3, $125.5,126.2,128.5,134.2,139.7,149.2$. MS $(\mathrm{M}+\mathrm{H})^{+}$calcd: 319.2; found: 319.6 .

tert-Butyl ((2R,3S)-4-(allyloxy)-3-azido-2-hydroxybutyl) (3-isopropyl-benzyl)carbamate (7). Compound 6 (228 mg, $0.7 \mathrm{mmol})$ was dissolved in $\mathrm{MeOH}(7 \mathrm{~mL})$. TEA $(200 \mu \mathrm{L}$, $1.4 \mathrm{mmol})$ and $\mathrm{Boc}_{2} \mathrm{O}(229 \mathrm{mg}, 1.0 \mathrm{mmol})$ were added and the mixture was stirred for $1 \mathrm{~h}$. The solution was concentrated and purified using flash column chromatography (toluene/EtOAc 19:1), which gave compound 7 (243 mg, $81 \%)$ as a colorless oil. ${ }^{1} \mathrm{H}-\mathrm{NMR}\left(\mathrm{CDCl}_{3}, 300 \mathrm{MHz}\right): \delta 1.25$ $(\mathrm{d}, J=6.9 \mathrm{~Hz}, 6 \mathrm{H}), 1.47(\mathrm{~s}, 9 \mathrm{H}), 2.85-2.94(\mathrm{~m}, 1 \mathrm{H}), 3.36$ (dd, $J=2.4,14.7 \mathrm{~Hz}, 1 \mathrm{H}), 3.45(\mathrm{td}, J=3.3,7.2 \mathrm{~Hz}, 1 \mathrm{H})$, 
$3.63(\mathrm{dd}, J=7.2,10.2 \mathrm{~Hz}, 1 \mathrm{H}), 3.72$ (bs, $1 \mathrm{H}), 3.79$ (bs, $1 \mathrm{H})$, $4.02(\mathrm{dt}, J=1.5,5.4 \mathrm{~Hz}, 2 \mathrm{H}), 4.45$ (bs, 2H), 4.63 (bs, 1H), 5.17-5.22 (m, 1H), 5.25-5.32 (m, 1H), 5.83-5.96 (m, $1 \mathrm{H})$, $7.09(\mathrm{~s}, 1 \mathrm{H}), 7.13-7.18(\mathrm{~m}, 2 \mathrm{H}), 7.23-7.24(\mathrm{~m}, 1 \mathrm{H}) ;{ }^{13} \mathrm{C}-$ NMR $\left(\mathrm{CDCl}_{3}, 75.5 \mathrm{MHz}\right): \delta 24.0,28.4,34.1,51.1,52.8$, 63.4, 70.1, 71.6, 72.3, 79.1, 117.3, 124.9, 125.3, 126.2, 129.0, 134.3, 137.7, 149.4, 153.1. MS $(\mathrm{M}+\mathrm{H})^{+}$calcd: 419.3; found: 419.5 .

tert-Butyl ((2R,3S)-4-(allyloxy)-3-amino-2-hydroxybutyl) (3-isopropyl-benzyl)carbamate (8). Compound 7 (114 mg, $0.3 \mathrm{mmol})$ was dissolved in $\mathrm{MeOH}(3 \mathrm{~mL})$. Aliquat $336(1$ drop), TEA (190 $\mu \mathrm{L}, 1.3 \mathrm{mmol})$ and 1,3-propanedithiol (135 $\mu \mathrm{L}, 1.3 \mathrm{mmol})$ were added to the solution and the mixture was stirred for 6 days at room temperature. The reaction mixture was filtered, concentrated and purified using flash column chromatography $(\mathrm{MeOH} /$ EtOAc $1: 9+1 \%$ TEA) to give compound $\mathbf{8}(82 \mathrm{mg}, 76 \%)$ as a colorless oil. ${ }^{1} \mathrm{H}-\mathrm{NMR}$ $\left(\mathrm{CDCl}_{3}, 300 \mathrm{MHz}\right): \delta 1.24(\mathrm{~d}, J=6.9 \mathrm{~Hz}, 6 \mathrm{H}), 1.46(\mathrm{~s}, 9 \mathrm{H})$, 2.84-2.93 (m, 3H), 2.96-3.02 (m, 1H), 3.35-3.39 (m, 1H), 3.44-3.49 (m, 2H), 3.55-3.57 (m, 1H), 3.75-3.85 (m, 1H), 3.96-3.98 (m, 2H), $4.50(\mathrm{bs}, 2 \mathrm{H}), 5.14-5.17(\mathrm{~m}, 1 \mathrm{H}), 5.21-$ $5.28(\mathrm{~m}, 1 \mathrm{H}), 5.81-5.94(\mathrm{~m}, 1 \mathrm{H}), 7.02-7.18(\mathrm{~m}, 3 \mathrm{H}), 7.21-$ $7.27(\mathrm{~m}, 1 \mathrm{H}) ;{ }^{13} \mathrm{C}-\mathrm{NMR}\left(\mathrm{CDCl}_{3}, 75.5 \mathrm{MHz}\right): \delta 24.1,28.5$, 34.2, 50.4, 52.4, 53.8, 71.8, 72.3, 73.6, 80.7, 117.3, 124.9, 125.4, 128.6, 134.6, 138.2, 149.3, 153.2. MS $(\mathrm{M}+\mathrm{H})^{+}$calcd: 393.3; found: 393.6 .

$(S)-1-((R)-2,2-D i m e t h y l-1,3-d i o x o l a n-4-y l) h e x-5-e n-1-o l$ (9a). Magnesium turnings (1.71 g, $70.3 \mathrm{mmol})$, a crystal of iodine and dry THF $(30 \mathrm{~mL})$ were mixed in a two-necked round-bottom flask equipped with a cooler. The mixture was heated gently and 5-bromopent-1-ene $(8.3 \mathrm{~mL}, 70.2 \mathrm{mmol})$ was added slowly to maintain a steady reflux. After the addition was complete, $30 \mathrm{~mL}$ of dry THF was added, and the solution was refluxed for $1 \mathrm{~h}$. The resulting Grignard mixture was thereafter cooled to $-30{ }^{\circ} \mathrm{C}$ and isopropylidene-protected D-glyceraldehyde (6.03 g, $46.4 \mathrm{mmol})$ dissolved in dry THF $(50 \mathrm{~mL})$ was added dropwise over a period of $30 \mathrm{~min}$. The resulting solution was allowed to obtain room temperature overnight, after which $\mathrm{Et}_{2} \mathrm{O}$ and saturated $\mathrm{NH}_{4} \mathrm{Cl}$ were added. The water phase was extracted with $\mathrm{Et}_{2} \mathrm{O}$ twice and the combined organic phases were dried, filtered and evaporated. The crude material was purified using flash column chromatography (heptane/EtOAc $10: 1)$ to yield 9a $(6.31 \mathrm{~g}$, $68 \%)$ as a colorless oil. $(S, R):{ }^{1} \mathrm{H}-\mathrm{NMR}\left(\mathrm{CDCl}_{3}, 300 \mathrm{MHz}\right)$ : $\delta 1.31-1.38(\mathrm{~m}, 1 \mathrm{H}), 1.36(\mathrm{~s}, 3 \mathrm{H}), 1.39-1.54(\mathrm{~m}, 2 \mathrm{H}), 1.42(\mathrm{~s}$, $3 \mathrm{H}), 1.57-1.68(\mathrm{~m}, 1 \mathrm{H}), 2.04-2.13(\mathrm{~m}, 2 \mathrm{H}), 2.15(\mathrm{~d}, J=3.5$ $\mathrm{Hz}, 1 \mathrm{H}), 3.71-3.80(\mathrm{~m}, 1 \mathrm{H}), 3.86-4.05(\mathrm{~m}, 3 \mathrm{H}), 4.93-5.06$ $(\mathrm{m}, 2 \mathrm{H}), 5.73-5.88(\mathrm{~m}, 1 \mathrm{H}) ;{ }^{13} \mathrm{C}-\mathrm{NMR}\left(\mathrm{CDCl}_{3}, 75.5 \mathrm{MHz}\right): \delta$ 25.1, 25.4, 26.6, 32.2, 33.7, 64.7, 70.7, 78.8, 109.0, 114.9, 138.5 .

1-((R)-2,2-Dimethyl-1,3-dioxolan-4-yl)hept-6-en-1-ol (9b). Compound 9b (9.62 g, total yield 87\%, $(S) /(R) 75: 25)$ was synthesized from isopropylidene-protected Dglyceraldehyde in the same manner as 9a. The two diastereomers were separated and collected as yellow oils. $(S, R):{ }^{1} \mathrm{H}-\mathrm{NMR}\left(\mathrm{CDCl}_{3}, 300 \mathrm{MHz}\right): \delta$ 1.31-1.64 (m, overlapped, 6H), 1.37 (s, overlapped, $3 \mathrm{H}), 1.43$ (s, overlapped, $3 \mathrm{H}), 1.93(\mathrm{~d}, J=3.0 \mathrm{~Hz}, 1 \mathrm{H}), 2.07$ (app. q, $J=6.6 \mathrm{~Hz}, 2 \mathrm{H})$, 3.76-3.81 (m, 1H), 3.88-3.97 (m, 2H), 3.99-4.06 (m, 1H), 4.93-5.04 (m, 2H), 5.74-5.87 (m, $1 \mathrm{H}) ;{ }^{13} \mathrm{C}-\mathrm{NMR}\left(\mathrm{CDCl}_{3}\right.$, $75.5 \mathrm{MHz}): \delta 25.4,25.5,26.6,29.0,32.6,33.8,64.6,70.8$,
78.8, 109.1, 114.6, 138.9. $\mathrm{MS}(\mathrm{M}+\mathrm{H})^{+}$calcd: 214.2 ; found: 213.9. $(R, R):{ }^{1} \mathrm{H}-\mathrm{NMR}\left(\mathrm{CDCl}_{3}, 300 \mathrm{MHz}\right): \delta 1.29-1.63(\mathrm{~m}$, overlapped, 6H), 1.37 (s, overlapped, 3H), 1.44 (s, overlapped, $3 \mathrm{H}), 2.04-2.10(\mathrm{~m}, 2 \mathrm{H}), 2.12(\mathrm{~d}, J=5.1 \mathrm{~Hz}, 1 \mathrm{H})$, 3.45-3.53 (m, 1H), 3.69-3.77 (m, 1H), 3.95-4.04 (m, 2H), 4.93-5.03 (m, 2H), 5.74-5.88 (m, $1 \mathrm{H}) ;{ }^{13} \mathrm{C}-\mathrm{NMR}\left(\mathrm{CDCl}_{3}\right.$, $75.5 \mathrm{MHz}): \delta 25.2,25.5,26.8,29.0,33.7,33.8,66.3,72.4$, 79.3, 109.5, 114.6, 138.9. MS $(\mathrm{M}+\mathrm{H})^{+}$calcd: 214.2 ; found: 213.8.

(R)-1-((R)-2,2-Dimethyl-1,3-dioxolan-4-yl)hex-5-en-1yl 4-nitrobenzoate (10a). To a solution of 9a (1.63 g, 8.15 mmol) in dry THF (50 mL), $p$-nitrobenzoic acid $(2.23 \mathrm{~g}, 13.3$ mmol) and $\mathrm{Ph}_{3} \mathrm{P}$ (3.42 g, $\left.13.0 \mathrm{mmol}\right)$ were added. DIAD $(2.57 \mathrm{~mL}, 13.1 \mathrm{mmol})$ was added dropwise over a period of $30 \mathrm{~min}$ and the resulting reaction mixture was stirred overnight at room temperature. After evaporation of the solvent, the crude remainder was purified by flash column chromatography (toluene $\rightarrow$ toluene/EtOAc 18:1) to furnish compound 10a $(2.60 \mathrm{~g}, 91 \%)$ as a slightly yellow oil. ${ }^{1} \mathrm{H}-\mathrm{NMR}$ $\left(\mathrm{CDCl}_{3}, 300 \mathrm{MHz}\right): \delta 1.35(\mathrm{~s}, 3 \mathrm{H}), 1.42-1.56(\mathrm{~m}, 2 \mathrm{H}), 1.45$ $(\mathrm{s}, 3 \mathrm{H}), 1.66-1.85(\mathrm{~m}, 2 \mathrm{H}), 2.03-2.19(\mathrm{~m}, 2 \mathrm{H}), 3.79(\mathrm{dd}$, $J=6.0,8.6 \mathrm{~Hz}, 1 \mathrm{H}), 4.03-4.12(\mathrm{~m}, 1 \mathrm{H}), 4.30(\mathrm{dd}, J=6.0$, $11.9 \mathrm{~Hz}, 1 \mathrm{H}), 4.92-5.06(\mathrm{~m}, 2 \mathrm{H}), 5.25(\mathrm{dt}, J=4.9,9.9 \mathrm{~Hz}$, $1 \mathrm{H}), 5.69-5.85(\mathrm{~m}, 1 \mathrm{H}), 8.23(\mathrm{~d}, J=9.2 \mathrm{~Hz}, 2 \mathrm{H}), 8.29(\mathrm{~d}$, $J=9.2 \mathrm{~Hz}, 2 \mathrm{H}) ;{ }^{13} \mathrm{C}-\mathrm{NMR}\left(\mathrm{CDCl}_{3}, 75.5 \mathrm{MHz}\right): \delta 24.6,25.3$, 26.4, 30.2, 33.4, 65.8, 75.3, 76.6, 109.8, 115.2, 123.6, 130.9, 135.7, 138.0, 150.7, 164.5. MS $(\mathrm{M}+\mathrm{H})^{+}$calcd: 350.2 ; found: 350.5 .

(R)-1-((R)-2,2-Dimethyl-1,3-dioxolan-4-yl)hex-5-en-1ol (11a). Compound 10a (2.55 g, $7.31 \mathrm{mmol})$ was dissolved in $\mathrm{MeOH}(40 \mathrm{~mL})$ and $\mathrm{NaOMe}$ in $\mathrm{MeOH}(0.5 \mathrm{M}, 15 \mathrm{~mL}, 7.5$ mmol) was added dropwise during $20 \mathrm{~min}$. The solution was stirred at room temperature for $1 \mathrm{~h}$ and $45 \mathrm{~min}$, after which it was neutralized with HOAc and evaporated. DCM and saturated $\mathrm{NaHCO}_{3}$ were added and the water phase was extracted with DCM once. The organic phases were dried, filtered and evaporated and the crude material was purified using flash column chromatography (heptane/EtOAc 9:1) to yield 11a $(1.00 \mathrm{~g}, 68 \%)$ as a colorless oil. ${ }^{1} \mathrm{H}-\mathrm{NMR}\left(\mathrm{CDCl}_{3}, 300\right.$ $\mathrm{MHz}): \delta 1.32-1.56(\mathrm{~m}, 3 \mathrm{H}), 1.36(\mathrm{~s}, 3 \mathrm{H}), 1.43(\mathrm{~s}, 3 \mathrm{H}), 1.57-$ $1.72(\mathrm{~m}, 1 \mathrm{H}), 2.01-2.14(\mathrm{~m}, 2 \mathrm{H}), 2.42(\mathrm{~d}, J=4.7 \mathrm{~Hz}, 1 \mathrm{H})$, 3.42-3.54 (m, 1H), 3.66-3.76 (m, 1H), 3.93-4.04 (m, 2H), 4.92-5.06 (m, 2H), 5.73-5.87 (m, 1H); ${ }^{13} \mathrm{C}-\mathrm{NMR}\left(\mathrm{CDCl}_{3}\right.$, $75.5 \mathrm{MHz}): \delta 24.8,25.4,26.7,33.0,33.6,66.2,72.1,79.3$, 109.4, 114.8, 138.5.

(S)-4-((S)-1-Azidohex-5-en-1-yl)-2,2-dimethyl-1,3dioxolane (12a). To a solution of 11 a $(993 \mathrm{mg}, 4.97 \mathrm{mmol})$ in dry THF $(30 \mathrm{~mL}), \mathrm{Ph}_{3} \mathrm{P}(2.06 \mathrm{~g}, 7.85 \mathrm{mmol})$ was added and the temperature was lowered to $-5^{\circ} \mathrm{C}$. DIAD $(1.60 \mathrm{~mL}$, $8.13 \mathrm{mmol})$ and DPPA $(2.17 \mathrm{~g}, 7.89 \mathrm{mmol})$ were added dropwise during $20 \mathrm{~min}$ and $5 \mathrm{~min}$, respectively, and the stirred solution was allowed to reach room temperature overnight. After evaporation of the solvent the crude mixture was purified using flash column chromatography $(2.5 \%$ EtOAc in heptane) to give 12a $(1.10 \mathrm{~g}, 98 \%)$ as a slightly yellow oil. ${ }^{1} \mathrm{H}-\mathrm{NMR}\left(\mathrm{CDCl}_{3}, 300 \mathrm{MHz}\right): \delta 1.28-1.46(\mathrm{~m}$, $1 \mathrm{H}), 1.35(\mathrm{~s}, 3 \mathrm{H}), 1.45(\mathrm{~s}, 3 \mathrm{H}), 1.47-1.70(\mathrm{~m}, 3 \mathrm{H}), 2.04-2.14$ $(\mathrm{m}, 2 \mathrm{H}), 3.44-3.53(\mathrm{~m}, 1 \mathrm{H}), 3.83-3.90(\mathrm{~m}, 1 \mathrm{H}), 3.98-4.10$ $(\mathrm{m}, 2 \mathrm{H}), 4.95-5.08(\mathrm{~m}, 2 \mathrm{H}), 5.72-5.86(\mathrm{~m}, 1 \mathrm{H}) ;{ }^{13} \mathrm{C}-\mathrm{NMR}$ $\left(\mathrm{CDCl}_{3}, 75.5 \mathrm{MHz}\right): \delta 25.3,25.5,26.3,30.4,33.4,63.7$, 
66.0, 78.0, 109.7, 115.2, 138.1. MS $(\mathrm{M}+\mathrm{H})^{+}$calcd: 226.2 ; found: 226.3 .

$(S)-4-((S)$-1-Azidohept-6-en-1-yl)-2,2-dimethyl-1,3dioxolane (12b). Compound 12b (357 mg, 88\%) was synthesized from $(R, R)-\mathbf{9 b}$ in the same manner as 12a and was collected as a colorless oil. ${ }^{1} \mathrm{H}-\mathrm{NMR}\left(\mathrm{CDCl}_{3}, 300 \mathrm{MHz}\right): \delta$ 1.34-1.47 (m, overlapped, 6H), 1.36 (s, overlapped, 3H), 1.46 (s, overlapped, $3 \mathrm{H}), 1.53-1.58(\mathrm{~m}, 2 \mathrm{H}), 3.45-3.49(\mathrm{~m}$, $1 \mathrm{H}), 3.84-3.91(\mathrm{~m}, 1 \mathrm{H}), 3.99-4.09(\mathrm{~m}, 2 \mathrm{H}), 4.93-5.05(\mathrm{~m}$, $2 \mathrm{H}), 5.73-5.87(\mathrm{~m}, 1 \mathrm{H}) ;{ }^{13} \mathrm{C}-\mathrm{NMR}\left(\mathrm{CDCl}_{3}, 75.5 \mathrm{MHz}\right): \delta$ $25.4,25.8,26.4,28.7,31.0,33.6,64.0,66.1,78.0,109.8$, 114.8, 138.6. MS $(\mathrm{M}+\mathrm{H})^{+}$calcd: 240.2 ; found: 239.9 .

(2S,3S)-3-Azidooct-7-ene-1,2-diol (13a). Compound 12a $(1.07 \mathrm{~g}, 4.76 \mathrm{mmol})$ was dissolved in a mixture of HOAc $(20 \mathrm{~mL})$ and $\mathrm{H}_{2} \mathrm{O}(10 \mathrm{~mL})$. The solution was stirred at $60{ }^{\circ} \mathrm{C}$ for $3 \mathrm{~h}$ after which the solvents were evaporated. The crude material was purified using flash column chromatography (toluene/EtOAc 2:1) to yield 13a $(650 \mathrm{mg}, 74 \%)$ as a colorless oil. ${ }^{1} \mathrm{H}-\mathrm{NMR}\left(\mathrm{CDCl}_{3}, 300 \mathrm{MHz}\right): \delta 1.40-1.72(\mathrm{~m}$, $4 \mathrm{H}), 2.02-2.18(\mathrm{~m}, 2 \mathrm{H}), 3.36-3.46(\mathrm{~m}, 1 \mathrm{H}), 3.57-3.75(\mathrm{~m}$, $3 \mathrm{H}), 3.85$ (br s, 1H), 4.10 (br s, 1H), 4.95-5.08 (m, 2H), 5.72-5.87 (m, $1 \mathrm{H}) ;{ }^{13} \mathrm{C}-\mathrm{NMR}\left(\mathrm{CDCl}_{3}, 75.5 \mathrm{MHz}\right): \delta 25.5$, $29.8,33.3,63.2,64.4,73.9,115.1,138.0$. MS-analysis resulted in decomposition. No mass peak could be detected.

(2S,3S)-3-Azidonon-8-ene-1,2-diol (13b). Compound 13b (290 mg, quant.) was synthesized from 12b in the same manner as 13a and was collected as a colorless oil. ${ }^{1} \mathrm{H}-\mathrm{NMR}$ $\left(\mathrm{CDCl}_{3}, 300 \mathrm{MHz}\right): \delta 1.41-1.49(\mathrm{~m}, 2 \mathrm{H}), 1.50-1.57(\mathrm{~m}, 2 \mathrm{H})$, 1.58-1.68 (m, 2H), 2.04-2.12 (m, 2H), 3.42-3.48 (m, $1 \mathrm{H})$, 3.67-3.69 (m, 1H), 3.71-3.75 (m, 2H), 4.94-5.05 (m, 2H), 5.74-5.87 (m, $1 \mathrm{H}) ;{ }^{13} \mathrm{C}-\mathrm{NMR}\left(\mathrm{CDCl}_{3}, 75.5 \mathrm{MHz}\right): \delta 25.8$, $28.8,30.5,33.6,63.3,64.8,73.6,114.8,138.6$. MS-analysis resulted in decomposition. No mass peak could be detected.

(2S,3S)-3-Azido-2-hydroxyoct-7-en-1-yl 4-methyl benzenesulfonate (14a). To a solution of 13a $(588 \mathrm{mg}, 3.18$ mmol) in a mixture of DCM $(50 \mathrm{~mL})$ and DMF $(10 \mathrm{~mL})$, TEA $(885 \mu \mathrm{L}, 6.35 \mathrm{mmol}), \mathrm{Bu}_{2} \mathrm{SnO}(81 \mathrm{mg}, 0.33 \mathrm{mmol})$ and $\mathrm{TsCl}(750 \mathrm{mg}, 3.93 \mathrm{mmol})$ were added. The reaction mixture was stirred at room temperature overnight. DCM and brine were added, and the organic phase was dried, filtered and evaporated. Flash column chromatography (toluene/EtOAc 9:1) afforded compound 14a (900 $\mathrm{mg}, 84 \%$ ) as a colorless oil. ${ }^{1} \mathrm{H}-\mathrm{NMR}\left(\mathrm{CDCl}_{3}, 300 \mathrm{MHz}\right): \delta 1.38-1.70(\mathrm{~m}, 4 \mathrm{H}), 2.01$ $2.14(\mathrm{~m}, 2 \mathrm{H}), 2.45(\mathrm{~s}, 3 \mathrm{H}), 2.64(\mathrm{~d}, J=5.0 \mathrm{~Hz}, 1 \mathrm{H}), 3.35-$ $3.46(\mathrm{~m}, 1 \mathrm{H}), 3.75-3.85(\mathrm{~m}, 1 \mathrm{H}), 4.07(\mathrm{dd}, J=6.6,10.4 \mathrm{~Hz}$, $1 \mathrm{H}), 4.17$ (dd, $J=3.1,10.4 \mathrm{~Hz}, 1 \mathrm{H}), 4.94-5-06(\mathrm{~m}, 2 \mathrm{H})$, 5.70-5.85 (m, 1H), $7.37(\mathrm{~d}, J=8.2 \mathrm{~Hz}, 2 \mathrm{H}), 2.83$ (d, $J=8.2$ $\mathrm{Hz}, 2 \mathrm{H}) ;{ }^{13} \mathrm{C}-\mathrm{NMR}\left(\mathrm{CDCl}_{3}, 75.5 \mathrm{MHz}\right): \delta 21.8,25.3,29.8$, 33.4, 63.6, 71.1, 71.6, 115.3, 128.1, 130.1, 132.5, 138.0, 145.5. MS-analysis resulted in decomposition. No mass peak could be detected.

(2S,3S)-3-Azido-2-hydroxynon-8-en-1-yl 4-methyl benzenesulfonate (14b). Compound 14b (395 mg, 88\%) was synthesized from 13b in the same manner as 14a and was collected as a pale yellow oil. ${ }^{1} \mathrm{H}-\mathrm{NMR}\left(\mathrm{CDCl}_{3}, 300\right.$ $\mathrm{MHz}): \delta 1.36-1.46(\mathrm{~m}, 3 \mathrm{H}), 1.49-1.57(\mathrm{~m}, 2 \mathrm{H}), 1.60-1.68$ $(\mathrm{m}, 1 \mathrm{H}), 2.03-2.10(\mathrm{~m}, 2 \mathrm{H}), 2.36-2.38(\mathrm{~m}, 1 \mathrm{H}), 2.46(\mathrm{~s}, 3 \mathrm{H})$, $3.38-3.44(\mathrm{~m}, 1 \mathrm{H}), 3.76-3.84(\mathrm{~m}, 1 \mathrm{H}), 4.08$ (dd, $J=6.6,10.5$ $\mathrm{Hz}, 1 \mathrm{H}), 4.19$ (dd, $J=3.0,10.5 \mathrm{~Hz}, 1 \mathrm{H}), 4.94-5.05(\mathrm{~m}, 2 \mathrm{H})$, 5.72-5.86 (m, 1H), $7.37(\mathrm{~d}, J=8.4 \mathrm{~Hz}, 2 \mathrm{H}), 7.81(\mathrm{~d}, J=8.4$
$\mathrm{Hz}, 2 \mathrm{H}) ;{ }^{13} \mathrm{C}-\mathrm{NMR}\left(\mathrm{CDCl}_{3}, 75.5 \mathrm{MHz}\right): \delta 21.8,25.5,28.7$, $33.6,63.7,71.1,71.7,114.9,128.2,130.2,132.6,138.5$, 145.5. MS-analysis resulted in decomposition. No mass peak could be detected.

$(S)$-2-((S)-1-Azidohex-5-en-1-yl)oxirane (15a). Compound 14a (320 mg, $0.94 \mathrm{mmol})$ was dissolved in $\mathrm{MeOH}(10$ $\mathrm{mL}$ ) and the temperature of the solution was lowered to $0{ }^{\circ} \mathrm{C}$. $\mathrm{Na}_{2} \mathrm{CO}_{3}(175 \mathrm{mg}, 1.65 \mathrm{mmol})$ was added and the stirred mixture was allowed to obtain room temperature overnight. Saturated $\mathrm{NH}_{4} \mathrm{Cl}$ was added and the resulting mixture was extracted with DCM. The organic phase was dried, filtered and evaporated and the crude remainder was purified using flash column chromatography (toluene) to provide the somewhat volatile 15a (157 mg, 100\%) as a colorless oil. ${ }^{1} \mathrm{H}-\mathrm{NMR}\left(\mathrm{CDCl}_{3}, 300 \mathrm{MHz}\right): \delta 1.43-1.72(\mathrm{~m}, 4 \mathrm{H}), 2.08$ $(\mathrm{q}, J=6.6 \mathrm{~Hz}, 2 \mathrm{H}), 2.72-2.79(\mathrm{~m}, 2 \mathrm{H}), 2.94-3.00(\mathrm{~m}, 1 \mathrm{H})$, 3.26-3.34 (m, 1H), 4.94-5.08 (m, 2H), 5.71-5.86 (m, $1 \mathrm{H})$; ${ }^{13} \mathrm{C}-\mathrm{NMR}\left(\mathrm{CDCl}_{3}, 75.5 \mathrm{MHz}\right): \delta 24.9,31.3,33.4,44.8,53.4$, $62.5,115.1,138.0$. MS $(2 \mathrm{M}+\mathrm{H})^{+}$calcd: 335.2 ; found: 335.6 .

$(S)$-2-((S)-1-Azidohept-6-en-1-yl)oxirane (15b). Compound 15b (192 $\mathrm{mg}, 97 \%)$ was synthesized from 14b in the same manner as 15a and was collected as a pale yellow oil. ${ }^{1} \mathrm{H}-\mathrm{NMR}\left(\mathrm{CDCl}_{3}, 300 \mathrm{MHz}\right): \delta 1.40-1.48(\mathrm{~m}, 2 \mathrm{H}), 1.50-1.60$ $(\mathrm{m}, 2 \mathrm{H}), 1.62-1.72(\mathrm{~m}, 2 \mathrm{H}), 2.04-2.12(\mathrm{~m}, 2 \mathrm{H}), 2.76-2.79$ $(\mathrm{m}, 1 \mathrm{H}), 2.80-2.83(\mathrm{~m}, 1 \mathrm{H}), 2.99-3.03(\mathrm{~m}, 1 \mathrm{H}), 3.31(\mathrm{dt}$, $J=5.1,8.1 \mathrm{~Hz}, 1 \mathrm{H}), 4.94-5.05(\mathrm{~m}, 2 \mathrm{H}), 5.74-5.87(\mathrm{~m}, 1 \mathrm{H})$; ${ }^{13} \mathrm{C}-\mathrm{NMR}\left(\mathrm{CDCl}_{3}, 75.5 \mathrm{MHz}\right): \delta 25.3,28.7,31.9,33.6,45.0$, 53.6, 62.8, 114.8, 138.6. MS $(2 \mathrm{M}+\mathrm{H})^{+}$calcd: 363.2 ; found: 362.9 .

(2R,3S)-3-Azido-1-((3-isopropylbenzyl)amino)oct-7en-2-ol (16a). Compound 15a (112 mg, $0.67 \mathrm{mmol})$ was dissolved in $\mathrm{MeOH}(1 \mathrm{~mL})$ and 3-isopropylbenzylamine (145 mg, $0.97 \mathrm{mmol})$ and TEA $(185 \mu \mathrm{L}, 1.33 \mathrm{mmol})$ were added. The solution was stirred overnight at $30{ }^{\circ} \mathrm{C}$ and was then evaporated. The crude material was purified using flash column chromatography (toluene/EtOAc $3: 1 \rightarrow$ toluene/EtOAc 1:1 + 1\% TEA), yielding compound 16a (130 $\mathrm{mg}, 61 \%)$ as a colorless oil. ${ }^{1} \mathrm{H}-\mathrm{NMR}\left(\mathrm{CDCl}_{3}, 300 \mathrm{MHz}\right): \delta$ $1.25(\mathrm{~d}, J=6.9 \mathrm{~Hz}, 6 \mathrm{H}), 1.34-1.80(\mathrm{~m}, 4 \mathrm{H}), 1.98-2.14(\mathrm{~m}$, $2 \mathrm{H}), 2.68(\mathrm{dd}, J=8.5,12.2 \mathrm{~Hz}, 1 \mathrm{H}), 2.81(\mathrm{dd}, J=3.6,12.2$ $\mathrm{Hz}, 1 \mathrm{H}), 2.84-2.96(\mathrm{~m}, 2 \mathrm{H}), 3.02(\mathrm{bs}, 2 \mathrm{H}), 3.32-3.42(\mathrm{~m}$, $1 \mathrm{H}), 3.58-3.67(\mathrm{~m}, 1 \mathrm{H}), 3.72(\mathrm{~d}, J=13.0 \mathrm{~Hz}, 1 \mathrm{H}), 3.80(\mathrm{~d}, J$ $=13.0 \mathrm{~Hz}, 1 \mathrm{H}), 4.92-5.07(\mathrm{~m}, 2 \mathrm{H}), 5.70-5.86(\mathrm{~m}, 1 \mathrm{H}), 7.07-$ $7.17(\mathrm{~m}, 2 \mathrm{H}), 7.21-7.29(\mathrm{~m}, 1 \mathrm{H}) ;{ }^{13} \mathrm{C}-\mathrm{NMR}\left(\mathrm{CDCl}_{3}, 75.5\right.$ MHz): $\delta 24.1,25.7,29.9,33.5,34.1,50.3,53.9,65.7,71.4$, $115.1,125.4,125.6,126.4,128.6,138.2,139.6,149.3$. MS $(\mathrm{M}+\mathrm{H})^{+}$calcd: 317.2 ; found: 317.6 .

(2R,3S)-3-Azido-1-((3-isopropylbenzyl)amino)non-8en-2-ol (16b). Compound 16b (177 mg, 53\%) was synthesized from $15 \mathbf{b}$ in the same manner as $\mathbf{1 6 a}$ and was collected as a colorless oil. ${ }^{1} \mathrm{H}-\mathrm{NMR}\left(\mathrm{CDCl}_{3}, 300 \mathrm{MHz}\right): \delta 1.26(\mathrm{~d}, J=$ $6.9 \mathrm{~Hz}, 6 \mathrm{H}), 1.37-1.50(\mathrm{~m}, 4 \mathrm{H}), 1.52-1.66(\mathrm{~m}, 2 \mathrm{H}), 2.04-2.11$ $(\mathrm{m}, 2 \mathrm{H}), 2.71(\mathrm{dd}, J=8.7,12.3 \mathrm{~Hz}, 1 \mathrm{H}), 2.85(\mathrm{dd}, J=3.6$, $12.3 \mathrm{~Hz}, 1 \mathrm{H}), 2.87-2.96(\mathrm{~m}, 1 \mathrm{H}), 3.36-3.42(\mathrm{~m}, 1 \mathrm{H}), 3.60-$ $3.66(\mathrm{~m}, 1 \mathrm{H}), 3.79(\mathrm{~d}, J=4.2 \mathrm{~Hz}, 2 \mathrm{H}), 4.94-5.05(\mathrm{~m}, 2 \mathrm{H})$, 5.74-5.88 (m, 1H), 7.11-7.16 (m, 3H), 7.25-7.30 (m, 1H); ${ }^{13} \mathrm{C}-\mathrm{NMR}\left(\mathrm{CDCl}_{3}, 75.5 \mathrm{MHz}\right): \delta 24.1,26.0,28.8,30.5,33.7$, $34.2,50.2,54.0,65.8,71.4,114.7,125.5,125.6,126.4$, 128.7, 138.7, 139.8, 149.4. MS $(\mathrm{M}+\mathrm{H})^{+}$calcd: 331.2 ; found: 330.9 . 
tert-Butyl ((2R,3S)-3-azido-2-hydroxyoct-7-en-1-yl)(3isopropylbenzyl)carbamate (17). Compound 17 (193 mg, $97 \%$ ) was synthesized from 16a according to the synthesis of compound 7 and was collected as a colorless oil. ${ }^{1} \mathrm{H}-\mathrm{NMR}$ $\left(\mathrm{CDCl}_{3}, 300 \mathrm{MHz}\right): \delta 1.25(\mathrm{~d}, J=6.9 \mathrm{~Hz}, 6 \mathrm{H}), 1.49(\mathrm{~s}, 9 \mathrm{H})$, 1.53-1.63 (m, 4H), 2.05-2.10 (m, 2H), 2.85-2.94 (m, 1H), 3.19-3.25 (m, 2H), 3.50-3.60 (m, 1H), 3.65-3.75 (m, 1H), 4.45 (bs, 2H), 4.94-5.05 (m, 2H), 5.71-5.85 (m, 1H), 7.04 (d, $J=7.5 \mathrm{~Hz}, 1 \mathrm{H}), 7.09$ (s, 1H), 7.14-7.19 (m, 1H), 7.24-7.29 $(\mathrm{m}, 1 \mathrm{H}) ;{ }^{13} \mathrm{C}-\mathrm{NMR}\left(\mathrm{CDCl}_{3}, 75.5 \mathrm{MHz}\right): \delta 24.1,25.6,28.5$, 29.7, 33.6, 34.2, 52.9, 54.9, 65.4, 74.2, 81.4, 115.2, 125.1, $125.9,128.8,137.8,138.2,149.6,153.3$. MS $(\mathrm{M}+\mathrm{H})^{+}$calcd: 417.2; found: 417.0 .

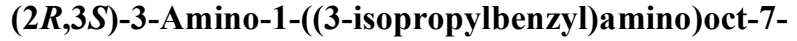
en-2-ol (18a). To a solution of 16a $(115 \mathrm{mg}, 0.36 \mathrm{mmol})$ in $\mathrm{MeOH}(1.5 \mathrm{~mL})$, TEA $(250 \mu \mathrm{L}, 1.79 \mathrm{mmol}), 1,3-$ propanedithiol $(180 \mu \mathrm{L}, 1.79 \mathrm{mmol})$ and Aliquat $336(2$ drops) were added. The solution was stirred at room temperature for 5 days, after which $1 \mathrm{M} \mathrm{HCl}, \mathrm{H}_{2} \mathrm{O}$ and DCM were added. The aqueous phase was washed with DCM and was then made basic with $1 \mathrm{M} \mathrm{NaOH}$. Subsequently, the water phase was extracted with EtOAc and the organic phase was dried, filtered and evaporated to yield 18a (88 $\mathrm{mg}, 83 \%$ ) as a colorless oil. ${ }^{1} \mathrm{H}-\mathrm{NMR}\left(\mathrm{CD}_{3} \mathrm{OD}, 300 \mathrm{MHz}\right): \delta 1.24(\mathrm{~d}$, $J=6.9 \mathrm{~Hz}, 6 \mathrm{H}), 1.27-1.60$ (m, 4H), 2.01-2.12 (m, 2H), 2.59$2.71(\mathrm{~m}, 2 \mathrm{H}), 2.72-2.83(\mathrm{~m}, 1 \mathrm{H}), 2.83-2.95(\mathrm{~m}, 2 \mathrm{H}), 3.59-$ $3.68(\mathrm{~m}, 1 \mathrm{H}), 3.73(\mathrm{~d}, J=13.0 \mathrm{~Hz}, 1 \mathrm{H}), 3.80(\mathrm{~d}, J=13.0 \mathrm{~Hz}$, $1 \mathrm{H}), 4.88-5.06(\mathrm{~m}, 2 \mathrm{H}), 5.72-5.90(\mathrm{~m}, 1 \mathrm{H}), 7.06-7.28(\mathrm{~m}$, $3 \mathrm{H}) ;{ }^{13} \mathrm{C}-\mathrm{NMR}\left(\mathrm{CD}_{3} \mathrm{OD}, 75.5 \mathrm{MHz}\right): \delta 24.5,26.6,32.7$, 34.8, 35.3, 51.3, 54.6, 56.0, 73.6, 115.2, 126.3, 127.0, 127.6, 129.5, 139.7, 140.5, 150.4. MS $(\mathrm{M}+\mathrm{H})^{+}$calcd: 291.2; found: 291.6.

(2R,3S)-3-Amino-1-((3-isopropylbenzyl)amino)non-8en-2-ol (18b). Compound 18b (128 mg, 81\%) was synthesized in the same manner as $\mathbf{1 8 a}$ from $\mathbf{1 6 b}$ and was collected as a colorless oil. ${ }^{1} \mathrm{H}-\mathrm{NMR}\left(\mathrm{CDCl}_{3}, 300 \mathrm{MHz}\right): \delta 1.24(\mathrm{~d}$, $J=6.9 \mathrm{~Hz}, 6 \mathrm{H}), 1.27-1.45(\mathrm{~m}, 6 \mathrm{H}), 2.01-2.08$ (m, 2H), 2.43 (bs, 3H), 2.67 (dd, $J=8.7,12.0 \mathrm{~Hz}, 1 \mathrm{H}), 2.79$ (dd, $J=3.6$, $12.0 \mathrm{~Hz}, 1 \mathrm{H}), 2.85-2.94(\mathrm{~m}, 2 \mathrm{H}), 3.54-3.59(\mathrm{~m}, 1 \mathrm{H}), 3.74(\mathrm{~d}$, $J=12.9 \mathrm{~Hz}, 1 \mathrm{H}), 3.82(\mathrm{~d}, J=12.9 \mathrm{~Hz}, 1 \mathrm{H}), 4.91-5.02(\mathrm{~m}$, $2 \mathrm{H})$, 5.72-5.85 (m, 1H), 7.11-7.16 (m, 3H), 7.22-7.27 (m, $1 \mathrm{H}) ;{ }^{13} \mathrm{C}-\mathrm{NMR}\left(\mathrm{CDCl}_{3}, 75.5 \mathrm{MHz}\right): \delta 24.1,26.0,29.0,33.1$, 33.7, 34.2, 50.0, 54.0, 54.5, 72.0, 114.6, 125.4, 125.7, 126.5, 128.6, 138.9, 139.7, 149.3. MS $(\mathrm{M}+\mathrm{H})^{+}$calcd: 305.3 ; found: 305.4 .

tert-Butyl ((2R,3S)-3-amino-2-hydroxyoct-7-en-1-yl) (3-isopropylbenzyl)carbamate (19). Compound 19 (151 $\mathrm{mg}, 88 \%$ ) was synthesized in the same manner as 18a from 17 and was collected as a colorless oil. ${ }^{1} \mathrm{H}-\mathrm{NMR}\left(\mathrm{CD}_{3} \mathrm{OD}\right.$, $300 \mathrm{MHz}): \delta 1.23(\mathrm{~d}, J=6.9 \mathrm{~Hz}, 6 \mathrm{H}), 1.27-1.60(\mathrm{~m}, 13 \mathrm{H})$, 2.03-2.10 (m, 2H), 2.67-2.72 (m, 1H), 2.82-2.92 (m, 1H), $3.00-3.10(\mathrm{~m}, 1 \mathrm{H}), 3.35-3.42(\mathrm{~m}, 1 \mathrm{H}), 3.65-3.80(\mathrm{~m}, 1 \mathrm{H})$, 4.35-4.50 (m, 1H), 4.55-4.65 (m, 1H), 4.89-5.02 (m, 2H), 5.74-5.87 (m, 1H), $7.03(\mathrm{~d}, J=7.5 \mathrm{~Hz}, 1 \mathrm{H}), 7.10 .7 .14(\mathrm{~m}$, 2H), 7.20.7.25 (m, 1H); ${ }^{13} \mathrm{C}-\mathrm{NMR}\left(\mathrm{CD}_{3} \mathrm{OD}, 75.5 \mathrm{MHz}\right): \delta$ 24.5, 26.7, 28.8, 32.7, 34.9, 35.3, 50.0, 53.1, 55.4, 74.7, 81.3, $115.1,125.8,126.3,129.5,139.7,150.3,158.0 . \mathrm{MS}(\mathrm{M}+\mathrm{H})^{+}$ calcd: 391.3; found: 391.0.

Methyl 3-(hydroxymethyl)-5-( $N$-methylmethylsulfonamido)benzoate (21a). A solution of 20a (1.65 g, 5.75 mmol) in THF (30 ml, dry) was flushed with $\mathrm{Ar}$ at $0^{\circ} \mathrm{C}$. After 10 minutes $\mathrm{BH}_{3} \mathrm{SMe}_{2}(930 \mu \mathrm{L}, 9.81 \mathrm{mmol})$ was added slowly and the mixture was left to reach room temperature and was stirred under Ar for 24 hours. The mixture was quenched with $\mathrm{MeOH}$, concentrated, re-dissolved in EtOAc, washed with $\mathrm{NaHCO}_{3}$ (sat. aq.) and brine. The organic phase was dried, filtered and concentrated. Finally, purification using flash column chromatography (toluene/EtOAc 3:1) gave compound 21a $(1.49 \mathrm{~g}, 95 \%)$ as white crystals. ${ }^{1} \mathrm{H}-$ $\mathrm{NMR}\left(\mathrm{CD}_{3} \mathrm{OD}, 300 \mathrm{MHz}\right): \delta 2.90(\mathrm{~s}, 3 \mathrm{H}), 3.33(\mathrm{~s}, 3 \mathrm{H}), 3.90$ (s, 3H), $4.66(\mathrm{~s}, 2 \mathrm{H}), 7.33$ (s, 1H), $7.65(\mathrm{~s}, 1 \mathrm{H}), 7.94(\mathrm{~s}, 1 \mathrm{H})$; ${ }^{13} \mathrm{C}-\mathrm{NMR}\left(\mathrm{CD}_{3} \mathrm{OD}, 75.5 \mathrm{MHz}\right): \delta 35.6,38.4,53.8,64.1$, $126.9,127.3,130.1,132.5,143.6,145.1,167.7$.

Methyl 3-(hydroxymethyl)-5-methylbenzoate (21b). Compound 21b $(6.8 \mathrm{~g}, 69 \%)$ was synthesized from 20b in the same manner as $21 \mathbf{a}$ and was collected as a colorless oil. ${ }^{1} \mathrm{H}-\mathrm{NMR}(\mathrm{CDCI} 3,400 \mathrm{MHz}) \delta 1.80(\mathrm{t}, J=5.9 \mathrm{~Hz}, 1 \mathrm{H}), 2.41$ (s, 3H), $3.91(\mathrm{~s}, 3 \mathrm{H}), 4.70(\mathrm{~d}, J=5.9 \mathrm{~Hz}, 2 \mathrm{H}), 7.40(\mathrm{~s}, 1 \mathrm{H})$, $7.79(\mathrm{~s}, 1 \mathrm{H}), 7.83(\mathrm{~s}, 1 \mathrm{H})$.

Methyl 3-formyl-5-( $\mathrm{N}$-methylmethylsulfonamido) benzoate (22a). A mixture of $\mathrm{SO}_{3}$-pyridine complex $(2.65 \mathrm{~g}$, $16.6 \mathrm{mmol})$ in dry DMSO $(8 \mathrm{~mL})$ was added to a solution of 21a $(1.42 \mathrm{~g}, 5.20 \mathrm{mmol})$ and TEA $(8.7 \mathrm{~mL}, 62.4 \mathrm{mmol})$ in DMSO $(17 \mathrm{~mL})$ and the mixture was stirred for 90 minutes at room temperature. Water was added and the product was extracted into EtOAc three times. The combined organic extracts were dried, filtered and concentrated. Finally, purification using flash column chromatography (toluene/EtOAc 3:1) gave compound 22a (1.18 g, 84\%) as a yellowish solid. ${ }^{1} \mathrm{H}-\mathrm{NMR}\left(\mathrm{CDCl}_{3}, 300 \mathrm{MHz}\right): \delta 2.91(\mathrm{~s}, 3 \mathrm{H}), 3.41(\mathrm{~s}, 3 \mathrm{H})$, $3.98(\mathrm{~s}, 3 \mathrm{H}), 8.09(\mathrm{~s}, 1 \mathrm{H}), 8.28(\mathrm{~s}, 1 \mathrm{H}), 8.43(\mathrm{~s}, 1 \mathrm{H}), 10.06$ $(\mathrm{s}, 1 \mathrm{H}) ;{ }^{13} \mathrm{C}-\mathrm{NMR}\left(\mathrm{CDCl}_{3}, 75.5 \mathrm{MHz}\right): \delta 36.0,37.9,52.8$, $129.4,129.8,131.8,132.6,137.6,143.0,165.2,190.5$.

Methyl 3-formyl-5-methylbenzoate (22b). Compound 22b $(4.9 \mathrm{~g}, 73 \%)$ was synthesized from $\mathbf{2 1 b}$ in the same manner as 22a and was collected as a white solid. ${ }^{1} \mathrm{H}-\mathrm{NMR}$ $\left(\mathrm{CDCl}_{3}, 300 \mathrm{MHz}\right): \delta 2.49(\mathrm{~s}, 3 \mathrm{H}), 4.00(\mathrm{~s}, 3 \mathrm{H}), 7.89(\mathrm{~s}, 1 \mathrm{H})$, $8.11(\mathrm{~s}, 1 \mathrm{H}), 8.32(\mathrm{~s}, 1 \mathrm{H}), 10.04(\mathrm{~s}, 1 \mathrm{H}) ;{ }^{13} \mathrm{C}-\mathrm{NMR}\left(\mathrm{CDCl}_{3}\right.$, $75.5 \mathrm{MHz}): \delta 21.2,52.6,129.0,131.3,133.5,136.0,136.8$, $139.6,163.5,191.7$.

Methyl 3-(1-hydroxyhex-5-en-1-yl)-5-( $N$-methyl methylsulfonamido) benzoate (23a). Freshly made pent-4enylmagnesium bromide in THF $(720 \mu \mathrm{L}, 0.65 \mathrm{mmol}, 0.9$ M) was added slowly to a solution of 22a (160 mg, 0.59 $\mathrm{mmol})$ in dry $\mathrm{Et}_{2} \mathrm{O}(20 \mathrm{~mL})$ and the mixture was stirred for 3 $\mathrm{h}$ at $0{ }^{\circ} \mathrm{C}$. The reaction was quenched with $\mathrm{NH}_{4} \mathrm{Cl}$ (sat. aq.) and the product was extracted into EtOAc three times. The combined organic extracts were dried, filtered and concentrated. Finally, purification using flash column chromatography (toluene/EtOAc 3:1) gave compound 23a (130 mg, $65 \%)$ as a colorless oil. ${ }^{1} \mathrm{H}-\mathrm{NMR}\left(\mathrm{CDCl}_{3}, 300 \mathrm{MHz}\right): \delta$ 1.66-1.81 (m, 4H), 2.05-2.12 (m, 2H), 2.23 (bs, 1H), 2.85 (s, $3 \mathrm{H}), 3.35(\mathrm{~s}, 3 \mathrm{H}), 3.93(\mathrm{~s}, 3 \mathrm{H}), 4.75(\mathrm{t}, J=6.4 \mathrm{~Hz}, 1 \mathrm{H})$, 4.93-5.03 (m, 2H), 5.71-5.84 (m, 1H), $7.61(\mathrm{~s}, 1 \mathrm{H}), 7.88(\mathrm{~s}$, $1 \mathrm{H}), 7.94(\mathrm{~s}, 1 \mathrm{H}) ;{ }^{13} \mathrm{C}-\mathrm{NMR}\left(\mathrm{CDCl}_{3}, 75.5 \mathrm{MHz}\right): \delta 25.0$, 33.5, 35.7, 38.2, 38.7, 52.5, 73.6, 115.0, 125.1, 126.0, 129.1, 131.6, 138.4, 142.0, 147.1, 166.3. MS $(\mathrm{M}+\mathrm{Na})^{+}$calcd: 364.1 ; found: 364.6.

Methyl 3-(1-hydroxyhex-5-en-1-yl)-5-methylbenzoate (23b). Compound 23b (580 mg, 79\%) was synthesized from 
22b in the same manner as 23a and was collected as a colorless oil. ${ }^{1} \mathrm{H}-\mathrm{NMR}\left(\mathrm{CDCl}_{3}, 300 \mathrm{MHz}\right): \delta$ 1.34-1.59 (m, 2H), 1.67-1.80 (m, 2H), 1.83-1.84 (m, 1H), 2.04-2.12 (m, 2H), $2.04(\mathrm{~s}, 3 \mathrm{H}), 3.91(\mathrm{~s}, 3 \mathrm{H}), 4.68-4.73(\mathrm{~m}, 1 \mathrm{H}), 4.92-5.03(\mathrm{~m}$, 2H), 5.71-5.85 (m, 1H), $7.37(\mathrm{~s}, 1 \mathrm{H}), 7.77(\mathrm{~s}, 1 \mathrm{H}), 7.80(\mathrm{~s}$, $1 \mathrm{H}) ;{ }^{13} \mathrm{C}-\mathrm{NMR}\left(\mathrm{CDCl}_{3}, 75.5 \mathrm{MHz}\right): \delta 21.4,25.2,33.7,38.7$, 52.2, 74.3, 114.9, 124.4, 129.5, 130.4, 131.3, 132.5, 138.6, 145.3, 164.4. MS $(\mathrm{M}+\mathrm{H})^{+}$calcd: 249.1; found: 249.5 .

Methyl 3-(hex-5-enoyl)-5-( $N$-methylmethylsulfonamido) benzoate (24a). Dess-Martin periodinane (248 $\mathrm{mg}, 0.59$ $\mathrm{mmol})$ was added to a solution of 23a $(133 \mathrm{mg}, 0.39 \mathrm{mmol})$ in DCM ( $3 \mathrm{~mL})$ and the solution was stirred for $24 \mathrm{~h}$ at room temperature. The solution was diluted with $\mathrm{Et}_{2} \mathrm{O}$ and washed with $\mathrm{Na}_{2} \mathrm{~S}_{2} \mathrm{O}_{3}$ and $\mathrm{NaHCO}_{3}$ (sat.). The organic phase was dried, filtered and concentrated. Purification using flash column chromatography (toluene/EtOAc 39:1) gave 24a (100 $\mathrm{mg}, 76 \%)$ as a colorless oil. ${ }^{1} \mathrm{H}-\mathrm{NMR}\left(\mathrm{CDCl}_{3}, 300 \mathrm{MHz}\right): \delta$ 1.81-1.91 (m, 2H), 2.13-2.20 (m, 2H), $2.87(\mathrm{~s}, 3 \mathrm{H}), 3.01(\mathrm{t}, J$ $=7.5 \mathrm{~Hz}, 2 \mathrm{H}), 3.38(\mathrm{~s}, 3 \mathrm{H}), 3.96(\mathrm{~s}, 3 \mathrm{H}), 4.99-5.09(\mathrm{~m}, 2 \mathrm{H})$, 5.75-5.89 (m, 1H), $7.95(\mathrm{~s}, 1 \mathrm{H}), 8.04(\mathrm{~s}, 1 \mathrm{H}), 8.38(\mathrm{~s}, 1 \mathrm{H})$; ${ }^{13} \mathrm{C}-\mathrm{NMR}\left(\mathrm{CDCl}_{3}, 75.5 \mathrm{MHz}\right): \delta 21.6,23.2,33.2,35.9,38.0$, 52.8, 115.7, 125.4, 127.8, 128.4, 129.2, 130.8, 138.0, 142.6, 165.7, 198.6. MS $(\mathrm{M}+\mathrm{H})^{+}$calcd: 340.1 ; found: 340.6 .

Methyl 3-(hex-5-enoyl)-5-methylbenzoate (24b). Compound 24b (317 mg, 89\%) was synthesized from 23b in the same manner as $\mathbf{2 4 a}$ and was collected as a colorless oil. ${ }^{1} \mathrm{H}$ NMR $\left(\mathrm{CDCl}_{3}, 300 \mathrm{MHz}\right): \delta 1.86$ (quintet, $J=7.2 \mathrm{~Hz}, 2 \mathrm{H}$ ), 2.13-2.20 (m, 2H), $2.46(\mathrm{~s}, 3 \mathrm{H}), 3.00(\mathrm{t}, J=7.2 \mathrm{~Hz}, 2 \mathrm{H})$, $3.95(\mathrm{~s}, 3 \mathrm{H}), 4.99-5.08(\mathrm{~m}, 2 \mathrm{H}), 5.76-5.90(\mathrm{~m}, 1 \mathrm{H}), 7.96(\mathrm{~s}$, $1 \mathrm{H}), 8.04(\mathrm{~s}, 1 \mathrm{H}), 8.38(\mathrm{~s}, 1 \mathrm{H}) ;{ }^{13} \mathrm{C}-\mathrm{NMR}\left(\mathrm{CDCl}_{3}, 75.5\right.$ $\mathrm{MHz}): \delta 21.3,23.4,33.2,38.0,52.4,115.5,126.7,130.7$, $132.8,134.5,137.5,138.1,139.0,166.6,199.7 . \mathrm{MS}(\mathrm{M}+\mathrm{H})^{+}$ calcd: 247.1 ; found: 247.5 .

tert-Butyl $\quad((2 R, 3 S)-3-(3-(h e x-5-e n o y l)-5-(N$-methylmethylsulfonamido)benzamido)-2-hydroxyoct-7-en-1yl)(3-isopropylbenzyl)carbamate (25a). Aqueous $\mathrm{LiOH}$ $(40 \mathrm{mg} / \mathrm{mL}, 324 \mu \mathrm{L}, 0.54 \mathrm{mmol})$ was added to a solution of $24 \mathbf{a}(61 \mathrm{mg}, 0.18 \mathrm{mmol})$ in a mixture of dioxane $(10 \mathrm{~mL})$ and water $(5 \mathrm{~mL})$ and the solution was stirred at room temperature for $2 \mathrm{~h}$. After neutrilization with $1 \mathrm{M} \mathrm{HCl}$, the volatiles were evaporated and the crude remainder was dissolved in DMF $(10 \mathrm{~mL})$. DIPEA $(105 \mu \mathrm{L}, 0.60 \mathrm{mmol})$ and compound 19 (46 mg, $0.12 \mathrm{mmol}$ ) were added and the temperature was lowered to $0{ }^{\circ} \mathrm{C}$. HATU (59 mg, $0.16 \mathrm{mmol}$ ) was added and the solution was allowed to obtain room temperature overnight. The DMF was subsequently evaporated and the crude product was purified using flash column chromatography (toluene/EtOAc 3:1 $\rightarrow$ toluene/EtOAc 1:1) to give 25a (73 $\mathrm{mg}, 89 \%$ over two steps) as a colorless glue. ${ }^{1} \mathrm{H}-\mathrm{NMR}$ $\left(\mathrm{CDCl}_{3}, 300 \mathrm{MHz}\right): \delta 1.23(\mathrm{~d}, J=7.1 \mathrm{~Hz}, 6 \mathrm{H}), 1.47(\mathrm{~s}, 9 \mathrm{H})$, 1.50-1.67 (m, 4H), 1.78-1.91 (m, 2H), 2.00-2.20 (m, 5H), 2.80-2.93 (m, 1H), $2.87(\mathrm{~s}, 3 \mathrm{H}), 3.02(\mathrm{t}, J=7.3 \mathrm{~Hz}, 2 \mathrm{H})$, 3.25-3.42 (m, 2H), 3.38 (s, 3H), 3.95 (br s, 2H), 4.23 (br s, $1 \mathrm{H}), 4.43$ (br s, 2H), 4.87-5.09 (m, 4H), 5.67-5.89 (m, 2H), 6.94-7.29 (m, 3H), 7.34 (br s, 1H), 8.02-8.13 (m, 2H), 8.35 (br $\mathrm{s}, 1 \mathrm{H}) ;{ }^{13} \mathrm{C}-\mathrm{NMR}\left(\mathrm{CDCl}_{3}, 75.5 \mathrm{MHz}\right): \delta 23.2,24.1,25.8,28.5$, 28.6, 29.3, 33.1, 33.6, 34.1, 35.7, 38.0, 50.2, 52.2, 54.0, 73.1, $81.3,115.1,115.6,125.0,125.1,125.4,125.8,128.3,128.7$, 129.1, 136.0, 137.6, 137.9, 138.3, 138.4, 142.6, 149.5, 157.5, 166.0, 198.9. MS $(2 \mathrm{M}+\mathrm{Na})^{+}$calcd: 1417.7 ; found: 1417.1 .
3-(Hex-5-enoyl)- $N$-((2R,3S)-2-hydroxy-1-((3-isopropylbenzyl)amino)oct-7-en-3-yl)-5-methylbenzamide (25b). Compound 25b (117 mg, 85\% over two steps) was synthesized from 24b in the same manner as 25a using amine 18a instead of 19 and was collected as a white solid. $[\alpha]_{\mathrm{D}}+0.5(c$ $0.1, \mathrm{MeOH}) .{ }^{1} \mathrm{H}-\mathrm{NMR}\left(\mathrm{CD}_{3} \mathrm{OD}, 300 \mathrm{MHz}\right): \delta 1.20$ (d, $J=$ $6.9 \mathrm{~Hz}, 6 \mathrm{H}), 1.34-1.73(\mathrm{~m}, 6 \mathrm{H}), 1.74-1.86(\mathrm{~m}, 2 \mathrm{H}), 1.87-2.01$ $(\mathrm{m}, 1 \mathrm{H}), 2.04-2.20(\mathrm{~m}, 3 \mathrm{H}), 2.47(\mathrm{~s}, 3 \mathrm{H}), 2.79-2.93(\mathrm{~m}, 1 \mathrm{H})$, 2.96-3.18 (m, 3H), 3.83-3.92 (m, 1H), 3.95-4.05 (m, 1H), $4.14(\mathrm{~d}, J=13.2 \mathrm{~Hz}, 1 \mathrm{H}), 4.21(\mathrm{~d}, J=13.2 \mathrm{~Hz}, 1 \mathrm{H}), 4.88-$ $5.08(\mathrm{~m}, 4 \mathrm{H}), 5.73-5.92(\mathrm{~m}, 2 \mathrm{H}), 7.21-7.38(\mathrm{~m}, 3 \mathrm{H}), 7.73(\mathrm{~s}$, $1 \mathrm{H}), 7.96(\mathrm{~s}, 1 \mathrm{H}), 8.19(\mathrm{~s}, 1 \mathrm{H}) ;{ }^{13} \mathrm{C}-\mathrm{NMR}\left(\mathrm{CD}_{3} \mathrm{OD}, 75.5\right.$ $\mathrm{MHz}): \delta 21.2,24.2,24.4,26.6,30.4,34.1,34.3,35.1,38.8$, $51.0,52.5,54.3,70.7,115.2,115.6,128.4,128.5,128.6$, $129.1,130.1,132.8,133.3,135.5,138.6,139.3,139.5,140.5$, 151.2, 170.3, 201.9. HRMS calcd $(\mathrm{M}+\mathrm{H})^{+}: 505.3430$; found 505.3437. LC-MS Purity System A: $t_{\mathrm{R}}=3.15 \mathrm{~min}, 100 \%$; System B: $t_{\mathrm{R}}=1.89 \mathrm{~min}, 100 \%$.

tert-Butyl ((2R,3S)-3-(3-(hex-5-enoyl)-5-methylbenzamido)-2-hydroxyoct-7-en-1-yl)(3-isopropylbenzyl)carbamate (26). To a solution of $25 \mathbf{b}(40 \mathrm{mg}, 0.079 \mathrm{mmol})$ in $\mathrm{MeOH}(8 \mathrm{~mL})$ were added $\mathrm{Boc}_{2} \mathrm{O}(25 \mathrm{mg}, 0.11 \mathrm{mmol})$ and TEA $(22 \mu \mathrm{L}, 0.16 \mathrm{mmol})$. The mixture was stirred at room temperature for $3 \mathrm{~h}$, and the solvent was then evaporated. Flash column chromatography (toluene/EtOAc 6:1 $\rightarrow$ toluene/EtOAc 3:1) provided compound $26(31 \mathrm{mg}, 65 \%)$ as a colorless glue. ${ }^{1} \mathrm{H}-\mathrm{NMR}\left(\mathrm{CDCl}_{3}, 300 \mathrm{MHz}\right): \delta 1.22$ (d, $J=$ $6.9 \mathrm{~Hz}, 6 \mathrm{H}), 1.48(\mathrm{~s}, 9 \mathrm{H}), 1.50-1.65(\mathrm{~m}, 6 \mathrm{H}), 1.72-1.91(\mathrm{~m}$, $2 \mathrm{H}), 1.96-2.20(\mathrm{~m}, 4 \mathrm{H}), 2.44(\mathrm{~s}, 3 \mathrm{H}), 2.86$ (septet, $J=6.9$ $\mathrm{Hz}, 1 \mathrm{H}), 3.00$ (t, $J=7.3 \mathrm{~Hz}, 2 \mathrm{H}), 3.29(\mathrm{dd}, J=4.4,14.6 \mathrm{~Hz}$, $1 \mathrm{H}), 3.35-3.51(\mathrm{~m}, 1 \mathrm{H}), 3.92$ (br s, $1 \mathrm{H}), 4.03-4.27(\mathrm{~m}, 2 \mathrm{H})$, 4.33-4.56 (m, 2H), 4.87-5.09 (m, 4H), 5.67-5.90 (m, 2H), 6.92-7.28 (m, 3H), 7.78-7.90 (m, 2H), 8.18 (br s, $1 \mathrm{H}) ;{ }^{13} \mathrm{C}-$ NMR $\left(\mathrm{CDCl}_{3}, 75.5 \mathrm{MHz}\right): \delta 21.4,23.4,24.1,25.7,28.5$, $29.1,33.2,33.6,34.2,38.0,50.4,52.3,53.7,73.6,81.2$, $115.1,115.5,124.1,125.0,125.7,125.8,128.7,131.6,132.2$, $134.8,137.5,137.7,138.1,138.4,139.1,149.5,158.9,167.2$, 199.9. MS $(\mathrm{M}+\mathrm{H})^{+}$calcd: 605.4 ; found: 604.9 .

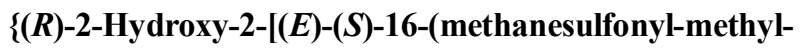
amino)-2,13-dioxo-3-aza-bicyclo[12.3.1] octadeca-1(17),8, 14,(18),15-tetraen-4-yl]-ethyl\}-(3-isopropyl-benzyl)-carbamic acid tert-butyl ester (27a). Compound 25a (65 mg, $0.093 \mathrm{mmol})$ was dissolved in dry DCM $(100 \mathrm{~mL})$ and the solution was degassed with $\mathrm{N}_{2}$. Hoveyda-Grubbs catalyst $2^{\text {nd }}$ generation (30 $\mathrm{mg}, 0.048 \mathrm{mmol}$ ) was added and the mixture was refluxed under $\mathrm{N}_{2}$ overnight. After evaporation of the solvent, the crude material was purified by flash column chromatography (toluene/EtOAc $3: 1 \rightarrow$ toluene/EtOAc 1:1) to yield $27 \mathbf{a}(13 \mathrm{mg}, 21 \%)$ as a colorless glue. ${ }^{1} \mathrm{H}-\mathrm{NMR}$ $\left(\mathrm{CDCl}_{3}, 300 \mathrm{MHz}\right): \delta 1.14-1.30(\mathrm{~m}, 2 \mathrm{H}), 1.23(\mathrm{~d}, J=6.9 \mathrm{~Hz}$, $6 \mathrm{H}), 1.34-2.38(\mathrm{~m}, 10 \mathrm{H}), 1.42(\mathrm{~s}, 9 \mathrm{H}), 2.65-3.15(\mathrm{~m}, 3 \mathrm{H})$, 2.87 (s, 3H), 3.20-3.53 (m, 2H), 3.35 (s, 3H), 3.93 (br s, 2H), 4.25-4.58 (m, 3H), 5.55-5.93 (m, 2H), 6.87-7.38 (m, 3H), 7.88-8.15 (m, 3H); ${ }^{13} \mathrm{C}-\mathrm{NMR}\left(\mathrm{CDCl}_{3}, 75.5 \mathrm{MHz}\right): \delta 24.8$, 25.4, 27.3, 28.4, 29.0, 29.5, 31.2, 32.2, 36.4, 37.9, 38.3, 50.1, $52.5,54.8,74.1,80.8,124.2,124.5,125.1,127.2,128.5$, $128.7,129.9,130.7,133.1,137.6,137.5,139.0,143.1,149.4$, 158.0, 167.8, 199.5. MS $(\mathrm{M}+\mathrm{H})^{+}$calcd: 670.4; found: 670.9.

$[(R)-2-H y d r o x y-2-((E)-(S)-16-m e t h y l-2,13-d i o x o-3-a z a-$ bicyclo[12.3.1] octadeca-1(17),8,14(18),15-tetraen-4-yl)- 
ethyl]-(3-isopropyl-benzyl)-carbamic acid tert-butyl ester (27b). Compound 27b (14 mg, 47\%) was synthesized in the same manner as 27a from $\mathbf{2 6}$ and was collected as a white powder. $[\alpha]_{\mathrm{D}}+16($ c $0.1, \mathrm{MeOH}) .{ }^{1} \mathrm{H}-\mathrm{NMR}\left(\mathrm{CDCl}_{3}, 300\right.$ $\mathrm{MHz}): \delta 1.21(\mathrm{~d}, J=6.9 \mathrm{~Hz}, 6 \mathrm{H}), 1.40(\mathrm{~s}, 9 \mathrm{H}), 1.42-2.30(\mathrm{~m}$, $11 \mathrm{H}), 2.44(\mathrm{~s}, 3 \mathrm{H}), 2.65-2.78(\mathrm{~m}, 1 \mathrm{H}), 2.81-2.96(\mathrm{~m}, 1 \mathrm{H})$, 2.97-3.12 (m, 1H), $3.31(\mathrm{dd}, J=4.1,14.2 \mathrm{~Hz}, 1 \mathrm{H}), 3.35-3.52$ (m, 1H), 3.84-4.07 (m, 2H), 4.34-4.62 (m, 3H), 5.71 (dt, $J=$ 6.3, $15.4 \mathrm{~Hz}, 1 \mathrm{H}), 5.78-5.91(\mathrm{~m}, 1 \mathrm{H}), 6.27$ (br s, 1H), 6.97$7.28(\mathrm{~m}, 3 \mathrm{H}), 7.78(\mathrm{~s}, 1 \mathrm{H}), 7.86-7.96(\mathrm{~m}, 2 \mathrm{H}) ;{ }^{13} \mathrm{C}-\mathrm{NMR}$ $\left(\mathrm{CDCl}_{3}, 75.5 \mathrm{MHz}\right): \delta 21.4,24.2,27.6,27.7,28.5,29.8$, $30.7,30.9,34.2,37.7,50.0,52.5,54.7,73.9,80.9,125.0$, $125.1,125.6,128.4,128.7,130.8,131.5,132.8,133.3,136.1$, $136.3,138.0,140.2,149.4,157.9,169.7,200.9$. HRMS calcd $(\mathrm{M}+\mathrm{H})^{+}:$577.3641; found 577.3647. LC-MS Purity System A: $t_{\mathrm{R}}=3.70 \mathrm{~min}, 100 \%$; System B: $t_{\mathrm{R}}=2.06 \mathrm{~min}, 98 \%$.

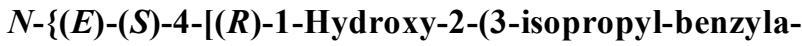
mino)-ethyl]-2,13-dioxo-3-aza-bicyclo[12.3.1]octadeca-1 (17),8,14(18),15-tetraen-16-yl\}-N-methyl-methanesulfonamide (28a). Compound 27a (13 $\mathrm{mg}, 0.019 \mathrm{mmol})$ was dissolved in a mixture of DCM $(10 \mathrm{~mL})$ and TFA $(2.5 \mathrm{~mL})$. Triethylsilane (TES) $(10 \mu \mathrm{L}, 0.063 \mathrm{mmol})$ was added and the solution was stirred at room temperature for $1 \mathrm{~h}$. The volatiles were evaporated and the remainder was dissolved in DCM and washed with $1 \mathrm{M} \mathrm{NaOH}$. The organic phase was dried, filtered and evaporated to yield $\mathbf{2 8 a}(10 \mathrm{mg}, 91 \%)$ as a colorless glue. $[\alpha]_{\mathrm{D}}+7(c 0.1, \mathrm{MeOH}) .{ }^{1} \mathrm{H}-\mathrm{NMR}\left(\mathrm{CDCl}_{3}\right.$, $300 \mathrm{MHz}): \delta 1.24(\mathrm{~d}, J=7.1 \mathrm{~Hz}, 6 \mathrm{H}), 1.43-2.11(\mathrm{~m}, 12 \mathrm{H})$, 2.12-2.27 (m, 2H), 2.70-2.80 (m, 2H), 2.82-2.93 (m, 1H), $2.88(\mathrm{~s}, 3 \mathrm{H}), 2.95-3.12(\mathrm{~m}, 1 \mathrm{H}), 3.35(\mathrm{~s}, 3 \mathrm{H}), 3.64-3.72(\mathrm{~m}$, $1 \mathrm{H}), 3.79(\mathrm{~s}, 2 \mathrm{H}), 3.87-3.98(\mathrm{~m}, 1 \mathrm{H}), 5.73(\mathrm{dt}, J=6.3,15.1$ $\mathrm{Hz}, 1 \mathrm{H}), 5.80-5.91(\mathrm{~m}, 1 \mathrm{H}), 6.08$ (d, $J=8.8 \mathrm{~Hz}, 1 \mathrm{H}), 7.09-$ $7.19(\mathrm{~m}, 2 \mathrm{H}), 7.21-7.29(\mathrm{~m}, 1 \mathrm{H}), 7.95-8.02(\mathrm{~m}, 2 \mathrm{H}), 8.04-$ $8.10(\mathrm{~m}, 1 \mathrm{H}) ;{ }^{13} \mathrm{C}-\mathrm{NMR}\left(\mathrm{CDCl}_{3}, 75.5 \mathrm{MHz}\right): \delta 24.2,27.4$, 28.4, 28.9, 29.8, 30.8, 34.2, 36.4, 37.6, 38.0, 51.3, 53.6, 54.2, $71.8,125.4,125.6,125.7,126.4,127.2,128.6,130.0,130.7$, $133.0,137.5,138.0,139.9,143.5,149.3,168.0,199.5$. HRMS calcd $(\mathrm{M}+\mathrm{H})^{+}:$570.3002; found 570.3011. LC-MS Purity System A: $t_{\mathrm{R}}=2.46 \mathrm{~min}, 97 \%$; System B: $t_{\mathrm{R}}=1.57$ $\min , 99 \%$.

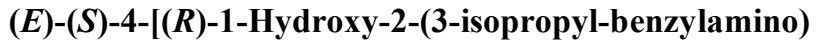
-ethyl]-16-methyl-3-aza-bicyclo[12.3.1]octadeca-1(17),8, 14(18),15-tetraene-2,13-dione (28b). Compound 28b (10 $\mathrm{mg}, \mathbf{9 1 \%}$ ) was synthesized from $\mathbf{2 7 b}$ in the same manner as 28a and was collected as a colorless glue. $[\alpha]_{\mathrm{D}}+11(c 0.1$, $\mathrm{MeOH}) .{ }^{1} \mathrm{H}-\mathrm{NMR}\left(\mathrm{CDCl}_{3}, 300 \mathrm{MHz}\right): \delta 1.24(\mathrm{~d}, J=6.9 \mathrm{~Hz}$, $6 \mathrm{H}), 1.47-1.68(\mathrm{~m}, 2 \mathrm{H}), 1.70-2.08(\mathrm{~m}, 8 \mathrm{H}), 2.10-2.37(\mathrm{~m}$, $2 \mathrm{H}), 2.41(\mathrm{~s}, 3 \mathrm{H}), 2.62-2.95(\mathrm{~m}, 5 \mathrm{H}), 2.96-3.10(\mathrm{~m}, 1 \mathrm{H})$, $3.65(\mathrm{q}, J=5.3 \mathrm{~Hz}, 1 \mathrm{H}), 3.76(\mathrm{~d}, J=13.5 \mathrm{~Hz}, 1 \mathrm{H}), 3.83(\mathrm{~d}, J$ $=13.5 \mathrm{~Hz}, 1 \mathrm{H}), 3.86-4.00(\mathrm{~m}, 1 \mathrm{H}), 5.67-5.91(\mathrm{~m}, 2 \mathrm{H}), 5.98$ $(\mathrm{d}, J=8.5 \mathrm{~Hz}, 1 \mathrm{H}), 7.08-7.26(\mathrm{~m}, 3 \mathrm{H}), 7.76(\mathrm{~s}, 1 \mathrm{H}), 7.84-$ $7.96(\mathrm{~m}, 2 \mathrm{H}) ;{ }^{13} \mathrm{C}-\mathrm{NMR}\left(\mathrm{CDCl}_{3}, 75.5 \mathrm{MHz}\right): \delta 21.4,24.2$, 27.5, 28.6, 29.3, 30.8, 30.9, 34.2, 37.8, 51.2, 53.7, 54.2, 72.2, $124.7,125.2,125.3,125.7,126.4$. HRMS calcd $(\mathrm{M}+\mathrm{H})^{+}$: 477.3117; found 477.3118. LC-MS Purity System A: $t_{\mathrm{R}}=$ $2.65 \mathrm{~min}, 96 \%$; System B: $t_{\mathrm{R}}=1.76 \mathrm{~min}, 97 \%$.

N-((S)-2-(Allyloxy)-1-((S)-2,2-dimethyl-1,3-dioxolan4-yl)ethyl)-3-(hex-5-enoyl)-5-methylbenzamide (29). Compound 24b (31 mg, $0.12 \mathrm{mmol}$ ) was dissolved in di- oxane $/ \mathrm{H}_{2} \mathrm{O}(2: 0.5 \mathrm{~mL})$ and aqueous $\mathrm{LiOH}(40 \mathrm{mg} / \mathrm{mL}, 150$ $\mu \mathrm{L}, 0.25 \mathrm{mmol})$ was added. The reaction mixture was stirred at room temperature for $6 \mathrm{~h}$ and then co-evaporated with toluene. The crude material was re-dissolved in DMF (1 $\mathrm{mL})$ and $(S)$-2-(allyloxy)-1-((S)-2,2-dimethyl-1,3-dioxolan4-yl)ethanamine (21 mg, $0.10 \mathrm{mmol})$, HATU (71 mg, 0.18 mmol) and DIPEA (65 $\mu \mathrm{L}, 0.37 \mathrm{mmol})$ were added. The reaction mixture was stirred at room temperature for $4 \mathrm{~h}$, evaporated and purified using flash column chromatography (toluene/EtOAc 3:1) to give compound 29 (25 mg, 57\%) as a colorless oil. ${ }^{1} \mathrm{H}-\mathrm{NMR}\left(\mathrm{CDCl}_{3}, 400 \mathrm{MHz}\right): \delta 1.50(\mathrm{~s}, 6 \mathrm{H})$, 1.61-1.67 (m, 2H), 2.14-2.18 (m, 2H), 3.04 (s, 3H), 2.57 (t, $J$ $=6.3 \mathrm{~Hz}, 2 \mathrm{H}), 3.59(\mathrm{dd}, J=6.8,11.6 \mathrm{~Hz}, 1 \mathrm{H}), 3.77(\mathrm{dd}, J=$ $6.0,9.9 \mathrm{~Hz}, 1 \mathrm{H}), 3.88-3.92(\mathrm{~m}, 2 \mathrm{H}), 3.99(\mathrm{dd}, J=6.0,9.9$ $\mathrm{Hz}, 1 \mathrm{H}), 4.04$ (d, $J=5.0 \mathrm{~Hz}, 2 \mathrm{H}), 4.56(\mathrm{~m}, 1 \mathrm{H}), 4.98-5.00$ $(\mathrm{m}, 1 \mathrm{H}), 5.01-5.03(\mathrm{~m}, 1 \mathrm{H}), 5.12(\mathrm{bs}, 1 \mathrm{H}), 5.13-5.15(\mathrm{~m}$, $1 \mathrm{H}), 5.67-5.75(\mathrm{~m}, 2 \mathrm{H}), 5.79-5.87(\mathrm{~m}, 1 \mathrm{H}), 7.93(\mathrm{~s}, 1 \mathrm{H})$, $8.02(\mathrm{~s}, 1 \mathrm{H}), 8.36(\mathrm{~s}, 1 \mathrm{H})$. MS $(\mathrm{M}+\mathrm{H})^{+}$calcd: 416.2 ; found: 416.2 .

N-((2S,3S)-1-(Allyloxy)-3,4-dihydroxybutan-2-yl)-3(hex-5-enoyl)-5-methylbenzamide (30). Compound 30 (656 $\mathrm{mg}, 95 \%$ ) was synthesized from 29 in the same manner as compound 3. ${ }^{1} \mathrm{H}-\mathrm{NMR}\left(\mathrm{CDCl}_{3}, 400 \mathrm{MHz}\right): \delta 0.95(\mathrm{~s}, 1 \mathrm{H})$, 1.54-1.60 (m, 2H), 2.13-2.18 (m, 2H), $2.36(\mathrm{~s}, 3 \mathrm{H}), 2.53(\mathrm{~s}$, $1 \mathrm{H}), 2.74(\mathrm{t}, J=6.3 \mathrm{~Hz}, 2 \mathrm{H}), 3.49(\mathrm{dd}, J=4.7,9.6 \mathrm{~Hz}, 1 \mathrm{H})$, $3.53-3.57(\mathrm{~m}, 2 \mathrm{H}), 3.70(\mathrm{dd}, J=4.7,9.7 \mathrm{~Hz}, 1 \mathrm{H}), 3.78(\mathrm{dd}, J$ $=1.3,9.9 \mathrm{~Hz}, 1 \mathrm{H}), 3.99(\mathrm{~d}, J=4.9 \mathrm{~Hz}, 2 \mathrm{H}), 4.10-4.12(\mathrm{~m}$, $1 \mathrm{H}), 4.73(\mathrm{~s}, 1 \mathrm{H}), 4.98-5.01(\mathrm{~m}, 1 \mathrm{H}), 5.02-5.05(\mathrm{~m}, 3 \mathrm{H})$, 5.64-5.72 (m, 1H), 5.75.5.83 (m, 1H), $7.92(\mathrm{~s}, 1 \mathrm{H}), 8.00(\mathrm{~s}$, $1 \mathrm{H}), 8.32(\mathrm{~s}, 1 \mathrm{H})$. MS $(\mathrm{M}+\mathrm{H})^{+}$calcd: 376.2 ; found: 376.1 .

$(E)-(S)-4-((S)-1,2-D i h y d r o x y-e t h y l)-16-m e t h y l-6-o x a-$ 3-aza bicyclo[12.3.1]octadeca-1(18),8,14,16-tetraene-2,13dione (31). Compound 31 (533 mg, 88\%) was synthesized from 30 in the same manner as compound $27 \mathbf{a}$ and was collected as a white powder. ${ }^{1} \mathrm{H}-\mathrm{NMR}\left(\mathrm{CDCl}_{3}, 400 \mathrm{MHz}\right): \delta$ $0.70(\mathrm{~s}, 1 \mathrm{H}), 1.70-1.76(\mathrm{~m}, 3 \mathrm{H}), 1.92-1.96(\mathrm{~m}, 2 \mathrm{H}), 2.41(\mathrm{~s}$, $3 \mathrm{H}), 2.73(\mathrm{t}, J=5.7 \mathrm{~Hz}, 2 \mathrm{H}), 3.48(\mathrm{dd}, J=1.6,9.8 \mathrm{~Hz}, 1 \mathrm{H})$, $3.55(\mathrm{dd}, J=4.0,9.9 \mathrm{~Hz}, 1 \mathrm{H}), 3.70(\mathrm{~m}, 1 \mathrm{H}), 3.73(\mathrm{dd}, J=$ 1.6, $9.8 \mathrm{~Hz}, 1 \mathrm{H}), 3.87(\mathrm{dd}, J=4.0,9.9 \mathrm{~Hz}, 1 \mathrm{H}), 4.02-4.06$ $(\mathrm{m}, 2 \mathrm{H}), 4.11-4.13(\mathrm{~m}, 1 \mathrm{H}), 5.54-5.63(\mathrm{~m}, 2 \mathrm{H}), 6.16(\mathrm{~s}, 1 \mathrm{H})$, $7.63(\mathrm{~s}, 1 \mathrm{H}), 7.79(\mathrm{~s}, 1 \mathrm{H}), 7.92(\mathrm{~s}, 1 \mathrm{H}) . \mathrm{MS}(\mathrm{M}+\mathrm{H})^{+}$calcd: 348.2; found: 348.1 .

Toluene-4-sulfonic acid $(S)-2-h y d r o x y-2-((E)-(S)-16-$ methyl-2,13-dioxo-6-oxa-3-aza-bicyclo[12.3.1]octadeca1(18),8,14,16-tetraen-4-yl)-ethyl ester (32). Compound 32 (434 mg, 57\%) was synthesized from 31 in the same manner as compound $\mathbf{4}$ and was collected as a white powder. ${ }^{1} \mathrm{H}$ NMR $\left(\mathrm{CDCl}_{3}, 400 \mathrm{MHz}\right): \delta 1.36(\mathrm{~s}, 1 \mathrm{H}), 1.71-1.76(\mathrm{~m}, 2 \mathrm{H})$, 1.92-1.96 (m, 2H), $2.37(\mathrm{~s}, 3 \mathrm{H}), 2.39(\mathrm{~s}, 3 \mathrm{H}), 2.73(\mathrm{t}, J=5.7$ $\mathrm{Hz}, 2 \mathrm{H}), 3.48(\mathrm{dd}, J=3.1,9.5 \mathrm{~Hz}, 1 \mathrm{H}), 3.58(\mathrm{dd}, J=5.6,9.9$ $\mathrm{Hz}, 1 \mathrm{H}), 3.69-3.75(\mathrm{~m}, 2 \mathrm{H}), 3.85(\mathrm{dd}, J=5.7,9.9 \mathrm{~Hz}, 1 \mathrm{H})$, 4.00-4.07 (m, 2H), $4.26(\mathrm{t}, J=5.6 \mathrm{~Hz}, 1 \mathrm{H}), 5.61-5.72(\mathrm{~m}$, $2 \mathrm{H}), 6.10(\mathrm{~s}, 1 \mathrm{H}), 7.46(\mathrm{~d}, J=6.0 \mathrm{~Hz}, 2 \mathrm{H}), 7.72(\mathrm{bs}, 1 \mathrm{H})$, 7.74 (bs, 1H), 7.89 (bs, 1H), 8.03 (d, $J=6.0 \mathrm{~Hz}, 2 \mathrm{H})$. MS $(\mathrm{M}+\mathrm{H})^{+}$calcd: 502.2; found: 502.1 .

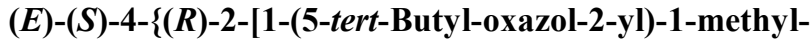
ethylamino]-1-hydroxy-ethyl $\}$-16-methyl-6-oxa-3-azabicyclo[12.3.1]octadeca-1(18),8,14,16-tetraene-2,13-dione 
(33). Compound 32 (199 $\mathrm{mg}, 0.40 \mathrm{mmol})$ was dissolved in EtOH (1.5 mL). 2-(5-(tert-butyl)oxazol-2-yl)propan-2-amine $(180 \mathrm{mg}, 0.99 \mathrm{mmol})$ and DIEPA $(1.5 \mathrm{~mL})$ were added and the reaction mixture was refluxed for 4 days. The solvent was evaporated and the crude material was purified using prep. LC-MS to give compound 33 (11 mg, 5\%). ${ }^{1} \mathrm{H}-\mathrm{NMR}$ $\left(\mathrm{CDCl}_{3}, 400 \mathrm{MHz}\right): \delta 1.40(\mathrm{~s}, 1 \mathrm{H}), 1.45(\mathrm{~s}, 9 \mathrm{H}), 1.62(\mathrm{~s}, 6 \mathrm{H})$, 1.72-1.76 (m, 2H), 1.92-1.96 (m, 2H), $2.45(\mathrm{~s}, 3 \mathrm{H}), 2.62(\mathrm{dd}$, $J=5.7,9.9 \mathrm{~Hz}, 1 \mathrm{H}), 2.73(\mathrm{t}, J=4.3 \mathrm{~Hz}, 2 \mathrm{H}), 2.87(\mathrm{dd}$, $J=5.7,9.9 \mathrm{~Hz}, 1 \mathrm{H}), 3.48(\mathrm{dd}, J=3.4,9.4 \mathrm{~Hz}, 1 \mathrm{H}), 3.69-3.75$ (m, 2H), 4.03-4.08 (m, 3H), $4.52(\mathrm{~s}, 1 \mathrm{H}), 5.59-5.69(\mathrm{~m}, 2 \mathrm{H})$, $6.17(\mathrm{~s}, 1 \mathrm{H}), 6.83(\mathrm{~s}, 1 \mathrm{H}), 7.62(\mathrm{bs}, 1 \mathrm{H}), 7.79(\mathrm{bs}, 1 \mathrm{H}), 7.98$ (bs, 1H). HRMS calcd $(\mathrm{M}+\mathrm{H})^{+}: 512.3119$; found 512.3109.

$N$-\{(E)-(S)-4-[(R)-1-Hydroxy-2-(3-isopropyl-benzylamino)-ethyl]-2,13-dioxo-6-oxa-3-aza-bicyclo[12.3.1] octadeca-1(17),8,14(18),15-tetraen-16-yl\}- $N$-methyl-

methanesulfonamide (34). Compound $\mathbf{3 4}$ was synthesized according to the synthetic route for $\mathbf{2 8 a}$, using compound $\mathbf{8}$ instead of 19, and was collected as a white solid. $[\alpha]_{\mathrm{D}}+41(c$ $0.1, \mathrm{MeOH}) .{ }^{1} \mathrm{H}-\mathrm{NMR}\left(\mathrm{CD}_{3} \mathrm{OD}, 300 \mathrm{MHz}\right): \delta 1.23(\mathrm{~d}$, $J=6.9 \mathrm{~Hz}, 6 \mathrm{H}), 1.74-1.94$ (m, 2H), 2.16-2.22 (m, 2H), 2.64$2.75(\mathrm{~m}, 1 \mathrm{H}), 2.78-2.93(\mathrm{~m}, 3 \mathrm{H}), 2.96(\mathrm{~s}, 3 \mathrm{H}), 3.19-3.28(\mathrm{~m}$, $1 \mathrm{H}), 3.38(\mathrm{~s}, 3 \mathrm{H}), 3.72(\mathrm{dd}, J=3.9,9.3 \mathrm{~Hz}, 1 \mathrm{H}), 3.83(\mathrm{~d}$, $J=6.9 \mathrm{~Hz}, 2 \mathrm{H}), 3.88-4.02$ (m, 3H), 4.08-4.17 (m, 2H), 5.84 (dt, $J=5.1,15.4 \mathrm{~Hz}, 1 \mathrm{H}), 5.98$ (dt, $J=6.7,15.4 \mathrm{~Hz}, 1 \mathrm{H})$, 7.12-7.16 (m, 2H), 7.21-7.27 (m, 2H), 8.04-8.05 (m, 1H), 8.10-8.11 (m, $1 \mathrm{H}), 8.21-8.22(\mathrm{~m}, 1 \mathrm{H}) ;{ }^{13} \mathrm{C}-\mathrm{NMR}\left(\mathrm{CD}_{3} \mathrm{OD}\right.$, $75.5 \mathrm{MHz}): \delta 22.8,25.8,30.0,33.4,34.5,35.8,36.6,51.2$, $52.7,52.9,68.3,70.2,124.8,125.2,125.9,126.3,126.9$, $127.8,128.3,129.3,131.9,136.2,136.4,137.5,142.6,148.6$, 167.2, 200.0. HRMS calcd $(\mathrm{M}+\mathrm{H})^{+}$: 572.2794; found 572.2797. LC-MS Purity System A: $t_{\mathrm{R}}=2.30 \mathrm{~min}, 100 \%$; System B: $t_{\mathrm{R}}=1.69 \mathrm{~min}, 100 \%$.

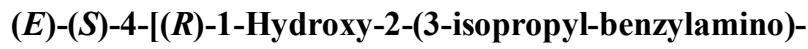
ethyl]-16-methyl-6-oxa-3-aza-bicyclo[12.3.1]octadeca-1 (17),8,14(18),15-tetraene-2,13-dione (35). Compound 35 was synthesized according to the synthetic route for $\mathbf{2 8 a}$, using compound $\mathbf{2 4 b}$ instead of $24 \mathbf{a}$ and compound 8 instead of 19, and was collected as a white solid. $[\alpha]_{\mathrm{D}}+92(c 0.1$, $\mathrm{MeOH}) .{ }^{1} \mathrm{H}-\mathrm{NMR}\left(\mathrm{CDCl}_{3}, 300 \mathrm{MHz}\right): \delta 1.24(\mathrm{~d}, J=6.9 \mathrm{~Hz}$, $6 \mathrm{H}), 1.77-1.98(\mathrm{~m}, 2 \mathrm{H}), 2.11-2.31(\mathrm{~m}, 2 \mathrm{H}), 2.48(\mathrm{~s}, 3 \mathrm{H})$, 2.74-2.82 (m, 2H), 2.84-2.92 (m, 2H), 2.94-3.04 (m, $1 \mathrm{H})$, $3.59(\mathrm{dd}, J=3.9,9.0 \mathrm{~Hz}, 1 \mathrm{H}), 3.73-3.79(\mathrm{~m}, 1 \mathrm{H}), 3.84(\mathrm{~d}$, $J=3.3 \mathrm{~Hz}, 2 \mathrm{H}), 3.90(\mathrm{dd}, J=4.5,12.6 \mathrm{~Hz}, 1 \mathrm{H}), 4.06-4.13$ $(\mathrm{m}, 1 \mathrm{H}), 4.22(\mathrm{dd}, J=2.7,9.0 \mathrm{~Hz}, 1 \mathrm{H}), 4.25-4.31(\mathrm{~m}, 1 \mathrm{H})$, 5.80-5.98 (m, 2H), 7.09-7.14 (m, 2H), $7.19(\mathrm{~s}, 1 \mathrm{H}), 7.22-$ $7.23(\mathrm{~m}, 1 \mathrm{H}), 7.91(\mathrm{~s}, 1 \mathrm{H}), 7.98(\mathrm{~s}, 1 \mathrm{H}), 8.00(\mathrm{~s}, 1 \mathrm{H}) ;{ }^{13} \mathrm{C}-$ NMR $\left(\mathrm{CDCl}_{3}, 75.5 \mathrm{MHz}\right): \delta 21.4,24.1,24.2,26.9,31.0$, $34.2,36.9,51.1,52.3,54.1,69.0,69.6,71.4,124.0,125.4$, $125.8,126.6,128.6,128.9,131.9,133.2,134.0,134.4,136.2$, $139.4,140.3,149.3,166.7,200.5$. HRMS calcd $(\mathrm{M}+\mathrm{H})^{+}$: 479.2910; found 479.2925. LC-MS Purity System A: $t_{\mathrm{R}}=$ $2.71 \mathrm{~min}, 98 \%$; System B: $t_{\mathrm{R}}=1.67 \mathrm{~min}, 99 \%$.

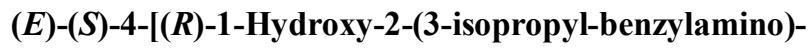
ethyl]-17-methyl-3-aza-bicyclo[13.3.1]nonadeca-1(18),9, 15(19), 16-tetraene-2,14-dione (36). Compound 36 was synthesized according to the synthetic route for $\mathbf{2 8 b}$, using compound 18b instead of 18a, and was collected as a white solid. $[\alpha]_{\mathrm{D}}+2.7\left(c\right.$ 0.1, MeOH). ${ }^{1} \mathrm{H}-\mathrm{NMR}\left(\mathrm{CD}_{3} \mathrm{OD}, 300 \mathrm{MHz}\right): \delta$ $1.23(\mathrm{~d}, J=6.9 \mathrm{~Hz}, 6 \mathrm{H}), 1.29-1.50(\mathrm{~m}, 2 \mathrm{H}), 1.56-1.74(\mathrm{~m}$, $4 \mathrm{H}), 1.78-1.89(\mathrm{~m}, 2 \mathrm{H}), 2.02-2.23(\mathrm{~m}, 4 \mathrm{H}), 2.44(\mathrm{~s}, 3 \mathrm{H})$,
2.54-2.64 (m, 1H), 2.77 (dd, $J=8.1,12.6 \mathrm{~Hz}, 1 \mathrm{H}), 2.82-2.94$ $(\mathrm{m}, 2 \mathrm{H}), 3.28-3.38(\mathrm{~m}$, overlapped of solvent peak, $1 \mathrm{H}), 3.71$ (dt, $J=3.3,7.8 \mathrm{~Hz}, 1 \mathrm{H}), 3.86(\mathrm{~d}, J=4.8 \mathrm{~Hz}, 2 \mathrm{H}), 3.88-3.95$ (m, $1 \mathrm{H}), 5.43(\mathrm{dt}, J=6.5,15.2 \mathrm{~Hz}, 1 \mathrm{H}), 5.60(\mathrm{dt}, J=6.9$, 15.2 Hz, 1H), 7.15-7.19 (m, 2H), 7.23-7.28 (m, 2H), 7.70 (s, $1 \mathrm{H}), 7.90(\mathrm{~s}, 1 \mathrm{H}), 8.06(\mathrm{~s}, 1 \mathrm{H}) ;{ }^{13} \mathrm{C}-\mathrm{NMR}\left(\mathrm{CD}_{3} \mathrm{OD}, 75.5\right.$ MHz): $\delta 21.3,24.4,25.7,27.8,29.2,31.2,32.5,32.8,35.4$, $38.2,52.6,54.2,55.2,73.3,126.8,127.0,127.4,128.0$, $129.7,130.8,131.8,133.4,134.1,137.2,137.4,138.8,141.0$, $150.6,171.2,202.8$. HRMS calcd $(\mathrm{M}+\mathrm{H})^{+}:$491.3274; found 491.3274. LC-MS Purity System A: $t_{\mathrm{R}}=2.96 \mathrm{~min}, 98 \%$; System B: $t_{\mathrm{R}}=1.78 \mathrm{~min}, 100 \%$.

\section{CONFLICT OF INTEREST}

The authors confirm that this article content has no conflict of interest.

\section{ACKNOWLEDGEMENTS}

We gratefully thank the following personnel at Medivir AB: Kurt Benkestock for helping us with HRMS measurements, Elizabeth Hamelink and Cathrine Åhgren for providing the inhibition data and Per-Ola Johansson. Finally, we would like to acknowledge Medivir AB for performing the $\mathrm{X}$-ray crystallography work and for financial support.

\section{SUPPLEMENTARY MATERIALS}

Supplementary material is available on the publishers web site along with the published article.

\section{PATIENT'S CONSENT}

Declared none.

\section{REFERENCES}

[1] Jakob-Roetne, R.; Jacobsen, H. Alzheimer's disease: from pathology to therapeutic approaches. Angew. Chem. Int. Ed. Engl., 2009, 48, 3030-59.

[2] Hardy, J. Amyloid, the presenilins and Alzheimer's disease. Trends Neurosci, 1997, 20, 154-9.

[3] Hunt, C. E.; Turner, A. J. Cell biology, regulation and inhibition of beta-secretase (BACE-1). FEBS. J., 2009, 276, 1845-59.

[4] Luo, Y.; Bolon, B.; Kahn, S.; Bennett, B. D.; Babu-Khan, S.; Denis, P.; Fan, W.; Kha, H.; Zhang, J.; Gong, Y.; Martin, L.; Louis, J. C.; Yan, Q.; Richards, W. G.; Citron, M.; Vassar, R. Mice deficient in BACE1, the Alzheimer's beta-secretase, have normal phenotype and abolished beta-amyloid generation. Nat. Neurosci., 2001, 4, 231-32.

[5] Roberds, S. L.; Anderson, J.; Basi, G.; Bienkowski, M. J.; Branstetter, D. G.; Chen, K. S.; Freedman, S. B.; Frigon, N. L.; Games, D.; Hu, K.; Johnson-Wood, K.; Kappenman, K. E.; Kawabe, T. T.; Kola, I.; Kuehn, R.; Lee, M.; Liu, W.; Motter, R.; Nichols, N. F.; Power, M.; Robertson, D. W.; Schenk, D.; Schoor, M.; Shopp, G. M.; Shuck, M. E.; Sinha, S.; Svensson, K. A.; Tatsuno, G.; Tintrup, H.; Wijsman, J.; Wright, S.; McConlogue, L. BACE knockout mice are healthy despite lacking the primary beta-secretase activity in brain: implications for Alzheimer's disease therapeutics. Hum. Mol. Genet., 2001, 10, 1317-24.

[6] Silvestri, R. Boom in the development of non-peptidic betasecretase (BACE1) inhibitors for the treatment of Alzheimer's disease. Med. Res. Rev., 2009, 29, 295-338.

[7] Beher, D.; Graham, S. L. Protease inhibitors as potential diseasemodifying therapeutics for Alzheimer's disease. Expert Opin. Investig. Drugs, 2005, 14, 1385-1409.

[8] AstraZeneca. (2014, 16 September). AstraZeneca and Lilly announce alliance to develop and commercialise BACE inhibitor 
AZD3293 for Alzheimer's disease [Press release]. Retrieved from http://www.astrazeneca.com/Media/Press-releases/Article/astrazeneca-and-lilly-announce-alliance

[9] Sandgren, V.; Agback, T.; Johansson, P. O.; Lindberg, J.; Kvarnström, I.; Samuelsson, B.; Belda, O.; Dahlgren, A. Highly potent macrocyclic BACE-1 inhibitors incorporating a hydroxyethylamine core: design, synthesis and X-ray crystal structures of enzyme inhibitor complexes. Bioorg. Med. Chem., 2012, 20, 4377-89.

[10] Stachel, S. J.; Coburn, C. A.; Sankaranarayanan, S.; Price, E. A.; Wu, G.; Crouthamel, M.; Pietrak, B. L.; Huang, Q.; Lineberger, J.; Espeseth, A. S.; Jin, L.; Ellis, J.; Holloway, M. K.; Munshi, S.; Allison, T.; Hazuda, D.; Simon, A. J.; Graham, S. L.; Vacca, J. P. Macrocyclic inhibitors of beta-secretase: functional activity in an animal model. J. Med. Chem., 2006, 49, 6147-150.

[11] Stachel, S. J.; Coburn, C. A.; Steele, T. G.; Crouthamel, M. C.; Pietrak, B. L.; Lai, M. T.; Holloway, M. K.; Munshi, S. K.; Graham, S. L.; Vacca, J. P. Conformationally biased P3 amide replacements of beta-secretase inhibitors. Bioorg. Med. Chem. Lett., 2006, 16, 64144.

[12] Martinelli, M. J.; Nayyar, N. K.; Moher, E. D.; Dhokte, U. P.; Pawlak, J. M.; Vaidyanathan, R. Dibutyltin oxide catalyzed selective sulfonylation of $\alpha$-chelatable primary alcohols. Org. Lett., 1999, 1, 447-50.

[13] Schmid, C. R.; Bryant, J. D.; Dowlatzedah, M.; Phillips, J. L.; Prather, D. E.; Schantz, R. D.; Sear, N. L.; Vianco, C. S. Synthesis of 2,3-O-1 sopropylidene-D-glyceraldehydein high chemical and optical purity: Observations on the development of a practical bulk process. J. Org. Chem., 1991, 56, 4056-58.

[14] Zuccarello, G.; Bouzide, A.; Kvarnström, I.; Niklasson, G.; Svensson, S. C. T.; Brisander, M.; Danielsson, H.; Nillroth, U.; Karlén, A.; Hallberg, A.; Classon, B.; Samuelsson, B. HIV-1 Protease Inhibitors Based on Acyclic Carbohydrates. J. Org. Chem., 1998, 63, 4898-4906.

[15] Stachel, S. J.; Coburn, C. A.; Steele, T. G.; Jones, K. G.; Loutzenhiser, E. F.; Gregro, A. R.; Rajapakse, H. A.; Lai, M. T.; Crouthamel, M. C.; Xu, M.; Tugusheva, K.; Lineberger, J. E.; Pietrak, B. L.; Espeseth, A. S.; Shi, X. P.; Chen-Dodson, E.; Holloway, M. K.; Munshi, S.; Simon, A. J.; Kuo, L.; Vacca, J. P. Structure-based design of potent and selective cell-permeable inhibitors of human beta-secretase (BACE-1). J. Med. Chem., 2004, 47, $6447-50$.
[16] Parikh, J. R.; Doering, W. V. E. Sulfur trioxide in the oxidation of alcohols by dimethyl sulfoxide. J. Am. Chem. Soc., 1967, 89, 550507.

[17] Dess, D. B.; Martin, J. C. Readily accessible 12-I-5 oxidant for the conversion of primary and secondary alcohols to aldehydes and ketones. J. Org. Chem., 1983, 48, 4155-56.

[18] Stachel, S. J. Progress toward the development of a viable BACE-1 inhibitor. Drug Dev. Res., 2009, 70, 101-10.

[19] Unpublished results.

[20] Probst, G. D.; Bowers, S.; Sealy, J. M.; Stupi, B.; Dressen, D.; Jagodzinska, B. M.; Aquino, J.; Gailunas, A.; Truong, A. P.; Tso, L.; Xu, Y. Z.; Hom, R. K.; John, V.; Tung, J. S.; Pleiss, M. A.; Tucker, J. A.; Konradi, A. W.; Sham, H. L.; Jagodzinski, J.; Toth, G.; Brecht, E.; Yao, N.; Pan, H.; Lin, M.; Artis, D. R.; Ruslim, L.; Bova, M. P.; Sinha, S.; Yednock, T. A.; Gauby, S.; Zmolek, W.; Quinn, K. P.; Sauer, J. M. Design and synthesis of hydroxyethylamine (HEA) BACE-1 inhibitors: structure-activity relationship of the aryl region. Bioorg. Med. Chem. Lett., 2010, 20, 6034-39.

[21] Sealy, J. M.; Truong, A. P.; Tso, L.; Probst, G. D.; Aquino, J.; Hom, R. K.; Jagodzinska, B. M.; Dressen, D.; Wone, D. W.; Brogley, L.; John, V.; Tung, J. S.; Pleiss, M. A.; Tucker, J. A.; Konradi, A. W.; Dappen, M. S.; Toth, G.; Pan, H.; Ruslim, L.; Miller, J.; Bova, M. P.; Sinha, S.; Quinn, K. P.; Sauer, J. M. Design and synthesis of cell potent BACE-1 inhibitors: structure-activity relationship of P1' substituents. Bioorg. Med. Chem. Lett., 2009, 19, 6386-91.

[22] Bäck, M.; Nyhlén, J.; Kvarnström, I.; Appelgren, S.; Borkakoti, N.; Jansson, K.; Lindberg, J.; Nyström, S.; Hallberg, A.; Rosenquist, $\AA$ A.; Samuelsson, B. Design, synthesis and SAR of potent statinebased BACE-1 inhibitors: exploration of P1 phenoxy and benzyloxy residues. Bioorg. Med. Chem., 2008, 16, 9471-86.

[23] Wångsell, F.; Gustafsson, K.; Kvarnström, I.; Borkakoti, N.; Edlund, M.; Jansson, K.; Lindberg, J.; Hallberg, A.; Rosenquist, Å.; Samuelsson, B. Synthesis of potent BACE-1 inhibitors incorporating a hydroxyethylene isostere as central core. Eur. J. Med. Chem., 2010, 45, 870-82.

[24] Artursson, P.; Karlsson, J. Correlation between oral drug absorption in humans and apparent drug permeability coefficients in human intestinal epithelial (Caco-2) cells. Biochem. Biophys. Res. Commun., 1991, 175, 880-85.

(C) Sandgren et al.; Licensee Bentham Open.

This is an open access article licensed under the terms of the Creative Commons Attribution Non-Commercial License (http://creativecommons.org/licenses/by-nc/3.0/) which permits unrestricted, non-commercial use, distribution and reproduction in any medium, provided the work is properly cited. 